\title{
EFFECT OF HIPPOCAMPAL STIMULATION ON FEEDING IN THE RAT
}

by

Norton William Milgram

\begin{abstract}
A thesis submitted to the Faculty of Graduate Studies and Research in partial fulfillment of the requirements for the degree of Doctor of Philosophy.
\end{abstract}

Department of Psychology

McGill University

June, 1968

Montrea 1 


\section{ACKNOWLEDGEMENTS}

This work was supported by the National

Research Council of Canada (Grant No. APB 66 to Dr. Peter Milner).

I wish to thank Dr. Peter Milner for his assistance in the preparation of this thesis and thanks are also due my wife Leah for aid with the histology . 
INTRODUCTION. . . . . . . . . . . 1

The role of the hypothalamus in feeding. . . 2 Extrahypothalamic structures and feeding . . 15

The present investigation. . . . . . 25

METHOD AND RESULTS. . . . . . . . . 27

General procedure. ......... 27

Experiment I ............. 32

ExperimentII . . . . . . . . . . 49

Experiment III ........... 63

GENERAL DISCUSSION. ........... 70

SUMMARY .............. 85

REFERENCES. . . . . . . . . . 86

FIGURES . . . . . . . . . . 104 


\section{INTRODUCTION}

The complexity of the mechanism regulating feeding behavior is becoming increasingly apparent. Peripheral input, (e.g., stomach distension, Kohn, 1951; taste and sme11, Teitelbaum, 1955; environmental temperature, Brobeck, 1960) centra1 input, (e.g., level of blood glucose, Mayer, 1953; brain temperature, Andersson \& Larsson, 1961; obscure hormonal factors, Davis, Gallagher \& Ladove, 1967) and psychological variables (e.g., previous experience, Baker, 1955) are all determinants of food intake. There is, however, little agreement on the relative importance of each of these factors (for recent reviews of these questions see Grossman, 1967 and Hamilton, 1965). Regardless of what fundamental changes are important in initiating and regulating food intake, it is generally assumed that the transduction of physiological signals to the behavior of seeking and eating food is a function of the central nervous system.

There are two aspects to the role of the central nervous system in the control and reguiation of food intake: the first anatomical, the second functional. Logically, this distinction appears unnecessary; empirically, the 
failure to make this distinction had led to difficulties. Almost exclusive attention has been focused on the hypothalamus, a sma11 neural structure located at the base of the brain. The neglect of other brain structures has resulted in serious misconceptions which will be considered in this review. The Role of the Hypothalamus in Feeding Behavior

Concern with the role of the hypothalamus in food regulation can be traced back to Erdheim in 1904 (cited by Grossman, 1967). In some previous clinical studies a marked obesity had been reported in humans with tumors located at the base of the brain. Erdheim attributed this effect to damage to the brain rather than to the nearby hypophysis. Confirmation was supplied by Bailey and Bremer (1921) who produced obesity in dogs by making small cuts at the base of the brain which did not damage the hypophysis. This finding was subsequently replicated in rats by Smith (1927) and later by Hetherington and Ranson (1940). The latter investigators then demonstrated that destruction of the ventromedial nucleus of the hypothalamus (VMH) was responsible for the obesity (Hetherington, 1944). 
Strange1y, lesions of the VMH produce increased feeding without a concomitant increase in food drive. Teitelbaum (1957) has reported that rats with such lesions will bar-press for food less frequently than normal rats if a high ratio of reinforcement is used. Furthermore, manipulation of the diet by the addition of a non-nutritive substance (Teitelbaum, 1955), or slight amounts of quinine (Corbit, 1965; Teitelbaum, 1955) markedly depresses caloric intake of animals with VMH lesions; control animals, however, are able to adjust their diet according to their energy requirements. The increased eating by animals with these lesions has, therefore, been attributed to a release phenomenon rather than a motivational factor. What seems to be lacking is a mechanism that stops eating once it has started.

Recently, experimental manipulation of the lateral region of the hypothalamus also has been found to affect food intake. Lesions to the lateral hypothalamic area (LH) produce severe aphagia (Anand \& Brobeck, 1951) which usually results in death from starvation unless the animals are nourished artifically (Teitelbaum \& Stellar, 
1954). Electrical stimulation of the same region can elicit eating in satiated animals (Brügger, 1943; Miller, 1957) which is in several respects similar to the feeding caused by normal hunger (Coons, Levak \& Miller, 1965; Wyrwicka, Dobrzecka \& Tarnecki, 1960). Thus, the latera1 hypothalamic region appears important primarily in initiating feeding behavior.

Both the proximity of the lateral and ventromedial hypothalamic regions to one another and their apparently opposite functions imply a dual control theory of food intake. This idea, first suggested by Anand and Brobeck (1951) and more recently espoused by Stellar (1954), Hoebel and Teitelbaum (1962) and many others, states essentially that feeding is initiated by lateral hypothalamic activity and continues until it is shut off by activity from the ventromedial nucleus. The simplicity and explanatory power of this theory is appealing. The necessity for an automatic mechanism ensuring proper nutrition is obvious from an evolutionary viewpoint. That such a mechanism would be located in a phylogenetically old part of the brain is equally obvious. It is, therefore; not surprising that 
similar effects of VMH lesions have been reported for the rodent (e.g., Hetherington \& Ranson, 1940), carnivore (e.g. Morgane \& Kosman, 1960) and primate (e.g., Hamilton \& Brobeck, 1964a). In the same vein, electrical stimulation of the lateral region has been found to induce eating in all species studied including the rodent (e.g., Miller, 1957), marsupial (e.g., Roberts, Steinberg \& Means, 1967), carnivore (e.g., Anand \& Dua, 1955), runinant (e.g., Larsson, 1954), and primate (e.g., Robinson \& Mishkin, 1962).

Attempts to demonstrate reciprocal relationships between LH and VMH have also been successful. Anand, Dua and Singh (1961) found that the electrical activity of the VMH is increased by the administration of glucose, a treatment which depresses food intake, and decreased by injectious of insulin, a treatment which increases feeding. LH activity, however was depressed by glucose and increased by insulin. Oomura, Ooyama, Yamamoto, Naka, Kobayashi and Ono (1967) reported that the spontaneous unit activity of VMH was depressed during LH stimulation and, conversely, 
VMH stimulation depressed LH unit activity. Fina11y, Hoebel and Teitelbaum (1962) observed that the reinforcing properties of lateral hypothalamic stimulation are augmented by both food deprivation and VMH lesions; both forced feeding and VMH stimulation have an opposite effect.

There are, however, some data which are difficult to account for on the basis of the dual control theory. Reynolds (1965) has pointed out that nearly all of the work demonstrating the importance of the VMH has been based on electrolytic lesions and he has demonstrated that complete destruction of the VMH by radio frequency coagulation does not produce hyperphagia in rats (Reynolds, 1963). Electrolys is is 1ikely to lead to either deposits of metallic ions in brain tissue or the generation of oxygen gas bubbles at the electrode tip, depending on the type of electrode and the direction of current flow. Reynolds proposes that this technique is likely to produce irritative scar tissue surrounding the lesion. The increased eating shown by animals with VMH damage might, therefore, be due to chronic irritation of the lateral hypothalamus. 
It should be mentioned that Reynolds' findings do not provide conclusive refutation of $\mathrm{VMH}$ involvement in food regulation. In contradiction to Reynolds' data, Hoebel (1965) has produced hyperphagia with radiofrequency lesions. Also, the irritative hypothesis can not account for some findings of studies using chemical stimulation of the brain. Epstein (1960) induced feeding in satiated rats by VMH injection of procaine, a neural depressant; VMH stimulation with hypertonic saline depressed eating in food-deprived rats. The discrepancy between Reynolds' evidence and that reported by other investigators may result from differences in the strain or sex of the animals used. Singh and Meyer (1968) were able to produce hyperphagia by VMH lesions only in female rats. This result, however, may indicate that VMH hyperphagia is due to hormonal disturbances, rather than to release of the lateral hypothalamus from inhibition.

The results of studies using electrical stimulation of the VMH raise further doubts as to the cause of VMH hyperphagia. Krasne (1962) disrupted feeding in rats by VMH stimulation; the same stimulation, 
however, interrupted drinking and motivated responding to terminate the stimulation. Similarly, Morgane (1966) found that VMH stimulation depressed self-stimulation from both lateral hypothalamic placements and other hypothalamic placements not involved with eating. These findings suggest that VMH stimulation is disruptive of general approach behavior, not specifically feeding. Conversely, the hyperphagia produced by VMH lesions may be caused by removal of an affective control mechanism, rather than a mechanism related exclusively to feeding (Grossman, 1966).

Morgane (1964) has criticized the dual control theory of food regulation on different grounds. He feels that the drastic effects of lateral hypothalamic lesions are due to interruption of nerve fibers passing through this region, rather than to destruction of cell bodies. Morgane has carried out a series of studies which support this viewpoint. He first demonstrated that the degree of aphagia produced by lateral hypothalamic lesions seems to be a function of the placement of the lesion. Although both mid-1ateral and far-1ateral lesions produced aphagia, the deficits shown by the 
animals with far-lateral lestons were much more severe, The retrograde degeneration following far-1ateral lesions extended upwards through the ansa lenticularis and lenticular fasciculus to the globus pallidus; there was no such fiber damage following mid-lateral lesions (Morgane, 1961a). Morgane (1961b) then made small bilateral leasons in the internal segment of the globus pallidus and in the fiber pathways leading from the globus pallidus to the far-lateral hypothalamic area. The feeding deficits in both groups were identical to those produced by far-lateral lesions. These findings suggest that the lateral hypothalamus contains two anatomically separate systems involved in food regulation. Morgane (1961c) has also presented evidence which he feels implicates the far-lateral region in motor control. of feeding and the mid-lateral regtion in food motivation (hunger). Rats recejving electrical stimulation of far-lateral placements would not only eat but would cross an electrified grid and perform a previously learned response for food. Lesions of the medial forebrain bundle (mid-lateral lesions) did not eliminate the feeding response to far-lateral stimulation 
but such S'B would no longer bar-press for food, nor would they cross an electrified grid. Morgane's hypothesis, however, would not account for the finding that rats receiving mid-1ateral stimulation would eat only if food were immediately available (Morgane, 1961c). Furthermore, far-lateral lesions apparently do not interrupt reflexive feeding responses (Rodgers, Epstein, \& Teitelbaum, 1965). It may be, as Morgane (1964) has more recently suggested, that the far-lateral region is important in the sequential organization of feeding responses. However, no data are directly applicable to this concept.

There is also evidence that the hypothalamic region anterior to the LH-VMH dual control center is important in the regulation of food intake. Electrical stimulation of the anterior preoptic region of the hypothalamus has been reported to elicit feeding in the monikey (Robinson, 1964) and the goat (Andersson, Gale \& Sundsten, 1964), Similarly, feeding following chemical stimulation has been observed in the rat (Coury, 1967). Localized thermal stimulation of this region also affects food intake; eating is increased 
by cooling and reduced by heating (Andersson, Gale \& Sundsten, 1964). Ablation of the preoptic area, on the other hand, is without effect unless the animals are heat stressed (Ham11ton \& Brobeck, 1.964b). Such animals do not eat less when the environmental temperature is high, though in such conditions the food intake of normal animals is severely depressed. These findings suggest that the anterior hypothalamus contains cells important in modulating food intake in the face of extreme temperature changes. The proximity of the preoptic area to the LH-VMH feeding areas makes it likely that these regions are intimately related; in any case, LH or VMH damage would probably cause destruction of preoptic fibers.

The possibility of connections from the VMH to the anterior preoptic region also exists. Stevenson (1964) found that rats with VMH lesions drastically. reduced their food intake when the environmental temperature was raised, Since the same conditions produced little change in the feeding of control animals ic would appear that the VMH has a modulatory effect on the preoptic area. 
Marked effects on feeding behavior have also been noted following lesions of the midbrain and other lower brainstem structures. These findings are considered in conjunction with the hypothalamus for two reasons. First, the mesencephalon is anatomically continuous with the more posterior regions of the hypothalamus; secondly it seems likely that any marked effects on feeding behavior following damage to this region of the brain are due to interruption of efferent hypothalamic pathways.

Aphagia in rats has been demonstrated following ventral midbrain destruction at a level likely to involve the basal optic root nuclei, and efther the ventral area of Tsai, or the mammillary peduncie or possibly both (Routtenberg \& Kane, 1966). Thompson, Rich and Langer (1964) have observed aphagia in five out of nine rats with lesions in the ventral lateral mesencephalon at a point where extensive damage to the substantia nigra was observed. Finally, Parker and Feldman (1967) have reported aphagia in rats with bilateral lesions of the mesencephalic reticular formation at the level of the red nucleus. The degree of aphagia following 
these lesions is variable, Normal feeding is completely disrupted in some animals while other animals demonstrate only transient aphagias; this effect does not necessarily correlate with the size of the lesion (Parker \& Feldman, 1967). These findings suggest that ventral lateral mesencephalic lesions can produce considerable feeding deficits; the extent of the effect is most likely determined by the amount of destruction of a crucial, but yet undefined, part of this region.

Wyrwicka and Doty (1966) have reported that stimulation of the brainstem in the vicinity of the ventral tegmental area of Tsai reliably elicited feeding in five cats. This behavior was similar to the feeding observed following lateral hypothalamic stimulation in that it was stimulus bound and in that feeding responses were not observed in the absence of food though, the stimulation frequently elicited other motor movements. The ventral area of Tsai was probably damaged in all the lesion studies where aphagia was reported. This midbrain region is also intricately related to the lateral hypothalamus, In the rat, Wolf and Sutin (1966) followed the fiber degeneration resulting from discrete lateral 
hypothalamic lesions through the mesencephalon to the ventral tegmental area of Tsai. Wyrwicka and Doty (1966) reported that stimulation of the lateral hypothalamus of cats reliably evoked potentials in the ventral tegmental area. Thus, this mesencephalic region can be considered a primary projection center for descending fibers either originating in or passing through the lateral hypothalamus. Damage to descending lateral hypothalamic fibers might, therefore, account for the aphagias observed following ventral midbrain destruction.

Lesions in mesencephalic areas other than the ventral lateral tegmentum have resulted in increased feeding. This has been found in the monkey (Ruch, Patton \& Brobeck, 1942), the cat (Skultety \& Gary, 1962) and the rat (Ehrlich, 1963). In all these reports, damage was bilateral and in the vicinity of the central gray. Since hyperphagia has not been reported following conplete destruction of the central gray matter (Thompson, Rich \& Langer, 1964; and many others), the adjacent tegmentum seems to contain the crucial brain tissue. Insufficient evidence makes it difficult to determine the precise anatomical localization of this 
effect. However, Crosby, Humphrey, and Lauer, (1962) have suggested that the effects of central gray destruction are frequently due to damage to the dorsal longitudinal fasciculus, a proximal dorsal tegmental pathway. Since this pathway is thought to contain efferent fibers from the $\mathrm{VMH}$, it is not unreasonable to suggest that the hyperphagia be due to destruction of these fibers.

Extrah ypothalamic Structures and Feeding

The evidence implicating the hypothalamus in food regulation renders implausible the postulation of mesencephalic centers initiating and inhibiting feeding. By the same token, the findings that at least some of the effects of hypothalamic lesions are due to interruption of pallido-hypothalamic pathways and fibers originating from the preoptic area, raise strong doubts regarding the functional significance of the lateral and medial hypothalamic regions. The issue now becomes one of specifying where the hypothalamic fibers originate, or what other neural areas are functionally important in the control of food intake.

Until recently the only information relevant 
to this question was that temporal lobectomy in monkeys has been reported to cause obesity (Brown \& Schaefer, 1888) and peculiar patterns of feeding behavior (Klüver \& Bucy, 1939). Any effects of such gross operations, however, are difficult to interpret in terms of precise anatomical function. Two recent studies have placed the problem of extrahypothalamic involvement in feeding in a new perspective. Robinson and Mishkin (1962) and Robinson (1964) have recently completed a systematic investigation of those regions of the monkey brain (macaca mullata) which are involved in some aspects of feeding behavior. Using movable electrodes they have studied the effects of electrical stimulation on over 5800 different placements in 15 monkeys. Stimulus bound feeding was observed from 156 points; it is significant that over half of these were located outside the hypothalamus. (Over half of the hypothalamic placements were outside the lateral hypothalamic feeding area.) The extrahypothalamic structures from which this effect was observed included the septal nuclei, the anterior cingulate gyrus, the diagonal band of Broca, the 
amygdala and the midline thalamus.

Similar findings have been reported in the rat using chemical stimulation of the brain. This work originally stems from Grossman's discovery (Grossman, 1960) that chemical stimulation of the hypothalamus with norepinephrine and other adrenergic substances would reliably elicit feeding in the rat. Coury (1967) has subsequently explored the effects of adrenergic stimulation on a number of extrahypthalamic structures. Coury's observations with the rat parallel those reported by Robinson with the monkey. Increased eating was observed following adrenergic stimulation of the cingulate gyrus, the septal nuclei, the diagonal band, the anterior thalamus, the mammillary bodies and the dorso-medial region of the hippocampus; adrenergic stimulation of the hypothalamus outside the lateral hypothalamic feeding area also induced feeding. These findings can be criticized on the grounds that the effects of chemical stimulation could be due to diffusion of the chemicals to neighboring neural tissue or, more likely, the ventricular system (Routtenberg, 1967). This criticism might also 
explain the inability to replicate these findings with the cat, an animal with a larger brain (Fisher \& Coury, 1964; Hernández-Peón, Chávez-Ibarra, Morgane \& Timo-Iaria, 1963).

In the rat, however, further verification of the importance of these extrahypothalamic structures has been obtained from studies using electrical stimulation. Maire (1956) reported eating following electrical stimulation of the mammillary bodies and the anterior thalamus. Smith, McFarland and Teitelbaum (1961) also have found eating following stimulation of the anterior thalamus, though the eating occurred only after stimulation induced convulsions. Fina11y, Miller (1963) reported that stimulation of a number of extrahypothalamic structures caused a delayed eating beginning from 4-8 minutes after the offset of stimulation, and continuing for 3-8 minutes. Placements where this was observed included the anterior thalamus, the paraventricular nucleus, the prehippocampal area, and the cingulate gyrus. Al1 these neural structures appear to be anatomically related. Both Fisher and Coury (1964) and Morgane (1964) have suggested that the extram 
hypothalamic structures involved in feeding are components of the limbic circuit. This anatomical concept stems from a proposal by Papez (1937). He defined a neural circuit, now bearing his name, which included the hippocampus, fornix, mammillary bodies, anterior thalamus, cingulate gyrus and their incerconnections. Functionally, the circuit was thought to be involved in emotion. These ideas have subsequently been extended by Maclean (1949) and later Nauta (1958) to include a collection of subcortical structures which are: 1. Intimately interconnected 2, all related to the hypothalamus and 3. well developed in primitive mammals and some lower vertebrates. The data previously discussed suggest that the limbic system might be functionally important in the regulation of food intake. This argument is also appealing from an evolutionary viewpoint. Lower mammals lacking true cortices are able to regulate food intake.

Limbic system lesions have been reported to affect food intake. Increases in feeding have been found following lesions of the hippocampus (Kimble \& 
Coover, 1966), fornix bodies (Ehrlich, 1963), septal nuclei (Singh \& Meyer, 1968), and anterior forebrain at a point likely to interrupt efferent hippocampal, septal, and amygdaloid fibers (Pizzi \& Lorens, 1967). The significance of these findings, however, is unclear. In the voluminous literature dealing with limbic system lesions there is little mention of any effects of such lesions on feeding (an exception to this is the amygdala which will be considered separately). This fact is not surprising in so far as the magnitude of the increased feeding is small and transient (e.g., Kimble \& Coover, 1966). Furthermore, in spite of increased food intake, animals with limbic system lesions are apparently able to maintain body weight at normal levels (Kimble \& Coover, 1966; Pizzi \& Lorens, 1967; Singh \& Meyer, 1968). Limbic system destruction may also produce feeding deficits more subtle than the relatively gross Inability to regulate body weight properly seen with hypothalamic lesions. Covian (1967) found that septal area destruction caused a marked increase in sodium intake. Thus, septal lesions may produce a modification in choice of diet, an observation unlikely to be made in 
animals tested and only under standard laboratory feeding conditions. There is also evidence indicating that animals with limbic system lesions are more highly motivated for food than normal anima1s. More persistent bar-pressing for food reward has been noted in animals with septal lesions (E1len \& Powe11, 1962; Pubols, 1966) and hippocampal lesions (Niki, 1965). Similarly, animals with septal lesions (Raphelson, Isaacson, \& Douglas, 1966) and fornix lesions (Ehrlich, 1963) appear more strongly motivated for food in a runway than normal animals. Finally, Palmer and Lash (1968) found that hippocampal lesions had no effect on feeding when the animals were maintained on an ad lib. feeding schedule; the same animals, on a food deprivation schedule, both ate more and seemed to gain more weight. It is not necessary to assume damage to the feeding system in order to understand these results. Limbic lesions have frequently been reported to cause an increase in general activity (e.g., Green Beatty, \& Schwartzbaum, 1967). Furthermore, this increase has been found markedly potentiated by food-deprivation (e.g., Schma1tz \& Isaacson, 1967). Increases in feeding 
or food-motivated behavior might, therefore, represent an adaptive attempt to maintain energy stores in the face of increased metabolic requirements. The effects of limbic system lesions on activity may also be indicative of the role of these structures in food regulation since it is well known that the need for food is related with behavioral activation.

More is known about the role of the amygdala in food regulation than about the role of other limbic structures. Hyperphagia has been reported following bilateral amygdala lesions in the cat (Morgane \& Kosman, 1959) and rat (Grossman \& Grossman, 1963). Other investigators, however, have failed to obtain this result (Anand \& Brobeck, 1952). It now seems likely that the discrepancies are due to the location of the lesion within the amygdaloid complex (Green, Clemente, \& De Groot, 1957; Grossman \& Grossman, 1963).

Electrical stimulation of the amygdala has been found to inhibit eating in hungry animals (Fonberg \& Delgado, 1961; Grossman \& Grossman, 1963) and barpressing for food (Fonberg \& Delgado, 1961). This effect is restricted to specific regions within the 
amygdaloid complex. Chemical stimulation, however, is without effect unless the animals are food deprived. In this state, adrenergic stimulation of the ventral amygdala leads to increased feeding while stimulation with dibenzyline, an adrenergic blocking agent, depresses food intake (Grossman, 1964).

Functionally, the amygdala seems important for the discrimination of food objects on the basis of taste. Monkeys with amygdala destruction have been reported to eat both edible and inedible objects indiscriminately (Klüver \& Bucy, 1939) and to drink saccharine solutions which they had rejected preoperatively (Weiskrantz, cited from Deutsch \& Deutsch, 1966). In the cat, Fonberg and Delgado (1961) have reported that amygdala stimulation coincident with eating will cause subsequent avoidance of what had previously been a palatable food. There is also some electrophysiological evidence on this point. 0'Keefe (1967) found an amygdaloid cell that would fire during ingestion of one type of food but not another. The hypothesis that the amygdala is important in food selection would a1so account for some species differences. 
In genera1, deficits seen in amygdalectomized rats seems far less severe than those seen in amygdalectomized cats. This appears to parallel differences in feeding behaviur; cats are relatively finicky about what they will regard as food while rats can be described as indiscriminate eaters .

The amygdala is customarily thought to contain two nuclear groups: the basolateral and the corticomedial nucle1. The basolateral nucleus seems more important in feeding behavior. Since the primary efferent connections of the nucleus are to the overlying cortex it is not likely that the changes in feeding behavior following experimental manipulation of this region are due to interruption or stimulation of direct amygdala-hypothalamic pathways. There is experimental evidence on this question. Morgane and Kosman (1960) found that amygdalectomy of cats made hyperphagic by. VMH lesions resulted in a second stage of hyperphagia; also, the rate of initial weight gain in animals with simultaneous VMH and amygdala lesions was three times that of animals with only hypothalamic destruction. These findings imply that the role of the amygdala in 
food regulation is not dependent on the ventro-medial nucleus. White and Fisher (1965), on the other hand, found that amygdala stimulation caused cessation of feeding in rats, but this effect disappeared following VMH lesions. While this apparently contradicts Morgane and Kosman's findings, White and Fisher also found that neither bilateral lesions of the stria terminals nor bilateral damage to the tail of the caudate nucleus had any affect on the disruption of feeding produced by amygdala stimulation. Since these lesions would have interrupted any amygdala-hypothalamic pathway the significance of White and Fisher's findings is obscure.

The Present Investigation

The evidence reviewed indicates that the neuroanatomy of the feeding system is far more complex than is usually assumed and that theories dealing exclusively with the hypothalamus are likely to be either wrong or misleading. Extrahypothalamic structures are obviously important in the neural regulation of food intake. At present, however, there is not enough relevant research to permit any 
definite conclusions about the functional role of these structures. There is clearly a necessity for more attention to the roles of extrahypothalamic structures and of the interactions between different neural regions in food regulation.

The present investigation is concerned with the function of the hippocampus in the regulation of food intake. This problem was originally suggested by an observation of the behavior of three animals receiving hippocampal stimulation. In all three animals an increase in feeding appeared attributable to the stimulation. This was surprising in so far as there are no previous reports of electrical stimulation of the hippocampus causing a modification of feeding behavior. Increased eating caused by hippocampal stimulation would also not have been predicted from the results of studies using hippocampal lesions. It was, therefore, decided to investigate this finding further in the hope that the use of electrical stimulation would help clarify the questions of both the functional importance of extrahypothalamic structures in food regulation, and more specifically the function of the hippocampus. 


\section{METHOD AND RESULTS}

Genera1 Procedure

The primary problem investigated in these experiments was the effect of electrical stimulation of the rat hippocampus on feeding behavior. The techniques used for delivering stimulation were adaptations of the self-stimulation procedure originally developed by 01ds and Milner (1954). Subjects

The subjects used in all experiments were male hooded rats of the Royal Victoria Hospital strain. They were purchased from the Quebec Breeding Farm and weighed 150 to250 grams. The animals were allowed to adapt to the laboratory environment for at least two weeks before operation, during which time they were tamed by handiing. Following operation the S's were housed individually in plastic or steel cages with food and water continuously available.

Surgical and Histological Techniques

Bipolar electrodes were used for electrical stimulation of the brain. They were made by twisting together two pieces of insulated nichrome wire of 0.01 
inch diameter. Male Winchester pins were soldered to the ends of the wires and molded into a plug with dental cement. The electrodes were cut to the desired length, leaving bare only the tips of the wires. The distance between electrode tips was approximately $0.25 \mathrm{~mm}$. In saline solution these electrodes had an impedance of approximately $10 \mathrm{~K}$ ohms.

Rats were anaesthetized with nembutal $(54 \mathrm{mg} / \mathrm{Kg}$, injected intraperitonea11y) during the electrode implantation. Following a midline incision of the scalp, a hole was drilled in the sku1l for the electrode and three jewelers screws were inserted into the skull around the point where the electrode was to be placed. The electrode was then lowered into the brain to the desired depth with the aid of a Kopf Stereotaxic instrument. After the skull had dried the electrode assembly was fixed firmly in place with dental cement. Immediately after the operation the S's were given $0.05 \mathrm{cc}$ of Bicillin to help curb infection. This technique was slightly modified for S's with fimbria cuts since these animals underwent a twostage operation. In the first stage an angular approach was used in implanting the hippocampal electrode and a 
sma1l mound of dental cement was used to hold the electrode in place. The skin was pulled together over this mound with wound clips in order to facilitate reopening of the scalp. The second stage was performed two to three weeks later. The scalp was reopened and two large holes were drilled at points $1.0 \mathrm{~mm}$. 1ateral to the midline and $0.5 \mathrm{~mm}$. posterior to bregma. A thin brass blade with a cutting edge $2.5 \mathrm{~mm}$. was then angled through this hole to a depth that should have cut the entire fimbria.

When testing was completed, the animals were sacrificed with ether and perfused through the heart with normal saline followed by $20 \%$ formal-saline. The brains were removed and allowed to stand in a $20 \%$ ethanol solution for at least two days. Frozen sections $40 \mathrm{p}$ or $80 \mu$ thick were cut in the region of the electrode tract and mounted on glass slides. In some cases photographs were made using the wet section as a negative. After the brain sections had thoroughly dried they were stained with cresyl violet and 1 uxol fast blue. Determinations of the electrode placements and the extent of the lesions wexe based on the photographs of the wet sections and on 
microscopic analysis of the stained sections. Apparatus

Two different pieces of apparatus were used for measuring self-stimulation behavior: a shuttle box and a Skinner box. The shuttle box consisted of two wire-mesh platforms separated by a metal hurdle. Depression of one of the platforms closed a microswitch which activated a counter, a running-time meter and an electrical stimulator which delivered $60 \mathrm{~Hz}$. sine-wave stimulation. The stimulation was continuous, not intermittent as in Valenstein and Meyers' (1964) procedure. Thus, records were obtained of the number of times an animal crossed to the stimulation side and the total number of seconds which were spent there.

The Skinner box was an $8 \times 9.5 \times 9.5$ in. box (Scientific Prototype Corp.) with two clear plastic sides, a clear plastic top, and a grid floor. Protruding from one side was a metal bar two inches from the floor of the box. To the left of the bar was a water spout, and at the right of the bar was a food cup. Depression of the bar had exactly the same effects as depression of the platform in the shuttle box. 
For this reason it was originally expected that the S's performance in this apparatus would be similar to that in the shuttle box. However, this did not prove to be the case. In the Skinner box, animals received far less stimulation per minute than they did in the shuttle box, though they pressed the bar more frequently than they crossed back and forth to turn the stimulation on and off. The testing sessions in the Skinner box were consequently made longer than those in the shuttle box.

Some S's were tested in yet another apparatus. This was a Skinner box with two bars, one at each end, and a food cup located half-way between the two bars on the rear wall of the box. Depression of one bar delivered $60 \mathrm{~Hz}$. sine-wave stimulation; the other activated a fooddelivery mechanism which dropped a $45 \mathrm{mg}$. Noyes food pellet into the food cup. All S's that were tested in this apparatus have previously demonstrated good barpressing for electrical stimulation in the one-bar Skinner box. Measurement of Food and Water Intake

The amount of food eaten was determined by scattering a weighed quantity (approximately $50 \mathrm{gm}$.) of Purina rat pellets all over the floor of the testing 
apparatus. At the end of the experimental session the remaining pellets and the food crumbs, which were collected in a pan below the grid floor, were again weighed. The difference in weight was taken as the amount eaten. The maximum discrepancy in weight during testing sessions when no food was eaten was $-0.1 \mathrm{gm}$.

Water intake was determined with a Richter tube having $1.0 \mathrm{ml}$. graduations. The amount of drinking was estimated to the nearest $0.5 \mathrm{ml}$.

\section{EXPERIMENT I}

\section{Subjects}

Subjects were 18 male hooded rats weighing from 210 to 260 grams at the time of operation. Twelve S's had electrodes implanted in the dorso-lateral region of the hippocampus while six had electrodes aimed at the cingulate gyrus. The stereotaxic coordinates used for the hippocampal placements were $3.5 \mathrm{~mm}$. lateral from the midline, $3.5 \mathrm{~mm}$. posterior to bregma and $3.0 \mathrm{~mm}$. down from the surface of the skull. The coordinates intended for the cingulate placements were $0.5 \mathrm{~mm}$. lateral from the midline, $3.0 \mathrm{~mm}$. posterior to bregma 
and $2.0 \mathrm{~mm}$. down from the surface of the skull. Procedure

After a two-day recovery period, a11 of the subjects were given six practice sessions in the shuttle box with the stimulator fixed to deliver $30 \mu \mathrm{A}$ rms. sinewave stimulation. Training sessions in this apparatus lasted ten minutes and were given once a day. The side on which stimulation was present was alternated between sessions in order to control for the development of position preferences. At the beginning of every session the S's were placed on the non-stimulated side. On the last two practice sessions food pellets were scattered all over the side of the box on which stimulation was available.

The S's were then tested on four consecutive days. The procedure followed was identical to that on the last two practice sessions except that the current was changed to $20 \mu \mathrm{A} r \mathrm{~ms}$, on the third testing session, and to $40 \mu \mathrm{A}$ rms. On the fourth.

Following testing in the shuttle box, $15 \mathrm{~S}^{\prime} \mathrm{s}$ were tested for self-stimulation and eating in the Skinner box. (Four animals, all with hippocampal electrodes, were discarded from this phase of the 
experiment since three fe11 $i 11$ and the fourth lost an electrode pin.) Training to press the bar was accomplished by placing the animal in the box for 30 minutes each day with the stimulator set at $30 \mu \mathrm{A}$. If, after several such sessions, there was no evidence of intentional pressing for stimulation, the experimenter attempted to shape this response by pressing the bar when the rat approached it. If shaping produced no results, the S's were given continuous undisturbed sessions in the box for up to two hours. If there was still no evidence of bar-pressing, it was concluded that the $S$ would not learn to bar-press for stimulation. Those animals that learned to self-stimulate were given dally half-hour practice sessions, with food and water available, until their rate of bar-pressing seemed to have stabilized. They were then tested on three consecutive days. On the first day, drinking and self-stimulation were observed, but no food was provided. On the second day, drinking, eating and self-stimulation were all recorded. On the third day, food and water were again available but the stimulator was turned off. During the first two testing sessions the stimulator was set to 
deliver $30 \mu \mathrm{A}$ rms. Sine-wave current.

Four animals were selected for a third test using the two-bar Skinner box. These S's were given daily half-hour sessions in the apparatus untll it could be determined whether or not they were learning to press the food-bar for food. All of them initially pressed the food-bar more than would have been expected of a satiated animal but this could have been caused by transfer of the response from the previous self-stimulation situation. Three criteria were, therefore, used to decide whether or not the S's were pressing the food-bar in order to receive food. These criteria were: 1. Pressing the food-bar more than 30 times in the testing session. 2. Eating all of the pellets of food. 3. Approaching the food cup immediately after having pressed the foodbar and eating the food on a majority of the trials.

\section{RESULTS}

Self-Stimulation and Feeding in the Shuttle Box

The average number of seconds spent on the stimulated side of the box and the number of times that the S's crossed over to receive stimulation are shown in Table 1. In the absence of proper controls it can 
Hippocampa1 Group $\mathrm{N}=12 \quad$ Cortical Group $\mathrm{N}=6$

$\begin{array}{cccccc}\text { Day } & \begin{array}{c}\text { Current } \\ \mu \mathrm{A}\end{array} & \begin{array}{l}\text { Mean } \\ \text { Crossovers }\end{array} & \begin{array}{c}\text { Mean Total } \\ \text { Stimulation } \\ \text { Sec. }\end{array} & \begin{array}{l}\text { Mean } \\ \text { Crossovers }\end{array} & \begin{array}{c}\text { Mean Total } \\ \text { Stimulation } \\ \text { Sec. }\end{array} \\ 1 & 30 & 5.58 & 444.42 & 6.67 & 259.33 \\ 2 & 30 & 6.92 & 453.42 & 7.33 & 359.00 \\ 3 & 20 & 8.42 & 339.58 & 3.83 & 110.33 \\ 4 & 40 & 8.08 & 458.00 & 5.67 & 351.50\end{array}$

Tab1e 1. Mean Crossovers and Mean Total Stimulation during four ten-minute experimental sessions in the shuttle box. 
not be concluded with certainty that the animals found the stimulation reinforcing. This is particularly evident in the data from the S's with cortical electrodes (intended cingulate placements). On the basis of chance, each group would be expected tc spend $50 \%$ of the time on the stimulated side $(300 \mathrm{sec}$.$) . On the other hand, it$ might be argued that the animals would have habituated to the apparatus after six sessions in which case they would probably not leave the side of the box on which they had been placed if the stimulation had no motivational effect. It can be concluded that the S's did not find the stimulation aversive, for they did not learn to avoid the stimulation after six practice sessions in the apparatus .

Regardless of whether the stimulation was positively reinforcing, both groups spent a sufficient period of time on the stimulated side to permit investigation of the effect of stimulation on eating. The mean food intake for all testing sessions is given in Table 2. As a group, the Ss with hippocampal electrodes did not differ significantly from the controls on any testing session. Electrical stimulation may have 
Hippocampa1 Group N=12

Day Mean Food
Intake (gm)

1

2

3

4

\begin{abstract}
Median Food
\end{abstract} Intake

(gm)

0.03

0.05

0

0
Cortical Group N=6

$\begin{array}{cc}\text { Mean Food } & \text { Median Food } \\ \text { Intake } & \text { Intake } \\ (\mathrm{gm}) & (\mathrm{gm})\end{array}$

$-0.01$

0

$-0.01$

0

$0.01 \quad 0$

0

Table 2. Food intake during four ten-minute experimental sessions in the shuttle box. 
caused increased eating in some of the animals with hippocampal electrodes since three S's ate on both the testing sessions at $30 \mu \mathrm{A}$. These S's ate too little, however, to provide definite evidence of hippocampal involvement in food regulation. Self-Stimulation and Feeding in the Skinner Box

A11 nine of the S's with hippocampal electrodes and three of the six S's with cortical electrodes learned to bar-press for stimulation in the Skinner box. The rates of bar pressing and mean number of seconds that the bar was held down for the three experimental sessions are presented in Table 3 for those animals that learned to bar-press. The reinforcing nature of the stimulation can be seen by comparing the behavior of the S's on the first two days, when the stimulator was on, with that on the third day, when the stimulator was off. Since these differences are highly significant for both groups of S's it is, therefore, justifiable to classify all the S's with hippocampal electrodes and the three selected S's with cortical electrodes as self-stimulators.

The mean amounts of food eaten during the 
Hippocampal Group $\mathrm{N}=9$

Day

$$
\text { Mean Bar }
$$

Presses

1

2

3

106.56

90.78

27.11

\begin{abstract}
Mean Total
\end{abstract} Stimulation Sec.

121.89

107.33

33.89
Cortical Group $\mathrm{N}=3$

Mean Bar

Presses

62.00

104.33

53.00

89.67

12.33

15.67

Table 3. Mean bar-presses and mean total stimulation time during three thirty-minute experimental sessions in the Skinner box. Scores on Day 3 represent extinction scores. 
second and third experimental sessions are shown in Table 4 for the same groups of S's. During the stimulation session every hippocampal rat ate more than any rat with a cortical electrode. Since the difference in total amount of stimulation between the two groups is not significant $(\mathrm{df}=10 ; \mathrm{t}=.159$; p>.20) it is apparent that the eating is not merely a generalized accompaniment of stimulation. Furthermore, the rats with hippocampal electrodes ate significantly more during the session with stimulation than on the session without it ( $t$-test for the difference between two means for correlated samples, $d f=8 ; t=2.59 ; p<.025)$, indicating that the group differences are due to the stimulation and not to lesions produced during the operation or to other artifactual differences. The amount of drinking during the three experimental sessions is shown in Table 4. On all three sessions the S's with hippocampal electrodes drank more than those with cortical electrodes. However, the differences were sma11 and insignificant. Furthermore, the S's with hippocampal electrodes drank similar amounts whether the stimulation was present or not, 
Hippocampal Group $\mathrm{N}=9$

\begin{tabular}{|c|c|c|c|c|c|c|c|c|}
\hline Day & $\begin{array}{l}\text { Mean Food } \\
\text { Intake } \\
(\mathrm{gm})\end{array}$ & Range & $\begin{array}{l}\text { Mean Water } \\
\text { Intake } \\
(\mathrm{m} 1)\end{array}$ & Range & $\begin{array}{l}\text { Mean Food } \\
\text { Intake } \\
(\mathrm{gm})\end{array}$ & Range & $\begin{array}{l}\text { Mean Water } \\
\text { Intake } \\
\text { (m1) }\end{array}$ & Range \\
\hline 1 & & & 1.0 & $0-3.0$ & & & 0.3 & $0-1.0$ \\
\hline 2 & 2.9 & $.9-5.8$ & 1.6 & $0-3.0$ & 0.5 & $.3-.6$ & 0.3 & $0-1.0$ \\
\hline 3 & 0.7 & $0-1.9$ & 1.8 & $0-6.0$ & 0.3 & $0-.5$ & 0 & \\
\hline
\end{tabular}

Table 4. Food and water intake during three thirty-minute experimental sessions in the Skinner box.

Cortical Group $\mathrm{N}=3$ 
which makes it even less likely that the stimulation caused any modification of drinking behavior. The Behavior of Four S's in the Two-Bar Skinner Box

All of the S's tested in the two-bar Skinner box learned to press for stimulation during their first testing session. Two of the four animals learned to obtain food by pressing the food-bar by the fourth testing session. Both of these S's showed a reliable pattern of behavior. Typically, they would press the bar for stimulation, turn to press the food-bar and then immediately go to the food cup and eat the pellet of food. On the fourth testing session each of these animals ate approximately 60 pellets of food.

The other two S's did not appear to learn to press the food-bar for food, though they repeatedly approached the food cup, indicating that they had learned to find food. To facilitate acquisition of the bar-pressing response, both $S$ 's were put on a 23 hour food-deprivation schedule and placed in the apparatus while hungry. One of these S's learned to press the food-bar after two such sessions. When this $S$ was subsequently tested satiated, he behaved in a 
manner similar to that of the first two animals. The other S fell ill before acquiring the response for food and had to be eliminated from the experiment. Localization of Electrode Tips

A11 of the hippocampal placements were found to be in the medial or posterior region of the dorsolateral hippocampus. The placements ranged from 2.0 to $4.0 \mathrm{~mm}$. posterior to bregma, from 3.0 to $3.5 \mathrm{~mm}$. lateral to the midline and from 3.0 to $4.0 \mathrm{~mm}$. below the surface of the sku11. One electrode tip pierced the dentate gyrus; the others were all located in the hippocampus proper. Photographs of typical sections through the electrode tips are shown in Fig. 1. It can be seen that the brain damage is limited to that caused by the electrode implantation. No damage to neighboring structures was observed.

A11 of the intended cingulate placements were located in the cortical region slightly lateral to the cingulate gyrus. The electrode tips were located in the same posterior plane as those of animals with hippocampal placements but they were ali slightly above or barely penetrating the corpus callosum and were approximately 
$1.5 \mathrm{~mm}$. closer to the midline. For these S's, also, the damage observed seemed limited to that due to electrode implantation (Fig. 1). Inspection of electrode placements in the cortical animals revealed no distinction on an anatomical basis between the S's that learned to self-stimulate and those that did not. Some Behavioral Observations of Hippocampal Animals

Though systematic behavioral measurements were not recorded, observation indicated a marked similarity in the response of all animals to stimulation and in their patterns of bar pressing. Furthermore, the performance of a given $S$ was found to be highly consistent from session to session.

Customarily, an animal approached and pressed the bar once or twice every thirty seconds. The duration of each press was usually from 0.5 to 1.0 seconds. After releasing the bar, the $S$ turned away from it and usually remained immobile for a period lasting from a fraction of a second for some $S$ 's to several seconds for others. This was followed by a relatively long period of hyperactivity during which there was frequent rearing, sniffing, grooming, and locomotion. The next bar-press 
usually occurred towards the end of this hyperactive period.

Though eating was observed in all S's during the course of bar-pressing for hippocampal stimulation, it was possible to classify animals according to two different patterns of response. The first category included those S's in which the onset of eating consistently occurred following the offset of stimulation. The behavior of these animals was striking. Usually within one second of the offset of stimulation the animal would grab a pellet and eat voraciously. It would continue eating for 4 to 30 seconds and then approach and press the bar and repeat the same pattern of behavior. In an exploratory experiment some of these animals were left in the Skinner box for extended periods of time. One $S$ was found to repeat this pattern of behavior for as long as two hours, at the end of which time it had eaten over 14 grams of food. In general, however, there appeared to be a satiation effect since the eating tapered off after about eight grams of food has been consumed.

The second category applied to S's who ate 
frequently, though there was no apparent correlation between the occurrence of eating and the presentation of stimulation. These animals would sometimes eat without interruption for periods lasting up to five minutes but the total amount of food consumed in the 30 minute testing session was usually less than that consumed by the S's in the first category. Some animals did not fit either category. These animals occasionally ate immediately following stimulation but not invariably. The behavior of the S's in the shuttle box was quite different. On crossing over to the stimulated side of the box they remained relatively immobile for extended periods of time. Occasionally, however, they crossed back and forth rapidly. It seemed that when they remained on the stimulated side for more than a short period of time, they found it less easy to cross back to turn the stimulation off. A similar observation was infrequently made in the Skinner box. Sometimes S's held the bar down for several seconds. In these instances their posture was like that of the animals remaining on the stimulated side of the shuttle box. 
Weight Changes and the Occurrence of Convulsive Seizures The weights of the $15 \mathrm{~S}$ 's which completed the first two parts of the experiment were measured on the first day of testing and again 26 days later. The group of S's with cortical electrodes had a mean weight gain of 56 gm. with a range of 36 to $71 \mathrm{gm}$. For the S's with hippocampal electrodes the mean weight gain was $90 \mathrm{gm}$. and the range was 75 to $110 \mathrm{gm}$. Since all the animals with hippocampal electrodes showed more weight gain than did any in the cortical group, this difference is clearly significant.

Convulsive seizures frequently occurred as a result of stimulation. In the shuttle box no seizures were observed on the first session in the apparatus but they were frequent on subsequent sessions. Those that occurred in the Skinner box usually followed the first or second bar-press of a session. When the animal recovered there were no further convulsions on that day. Chewing movements were frequently observed during the recovery period following convulsive seizures. This response did not appear to be food-directed since it was not accompanied by feeding. 


\section{EXPERIMENT II}

Although Experiment I of this study is the first report that eating is elicited by electrical stimulation of the hippocampus, Coury (1967) found eating in rats following chemical stimulation of this structure. However, in my experiment all the animals had electrodes located in the dorso-lateral hippocampus, while Coury reported eating following chemical stimulation of the dorso-medial hippocampus and not after stimulation of the dorso-lateral hippocampus. Also, both Fisher and Coury (1962) and Coury (1967) found drinking following chemical stimulation of the hippocampus but I did not observe any changes in drinking which could be attributed to electrical stimulation. Since stimulation with carbachol elicited drinking in certain regions only, the electrode placements in my experiment may have missed the critical areas.

The second experiment was performed with the purpose of investigating the problem of localization of function within the hippocampus. Many loci throughout the dorsal and ventral hippccampus were tested for self-stimulation, eating, and drinking. Since it has 
been reported that self-stimulation cannot be obtained from all points within the hippocampus (Ursin, Ursin \& 01ds, 1966), a further test was devised to determine the effects of stimulation on eating and drinking in non self-stimulators.

Subjects

Subjects were 44 male hooded rats with electrodes implanted by the method previous1y described. The intended electrode placements were such as to sample the entire dorsal hippocampus, the dentate gyrus and the ventral hippocampus. Procedure

After a Lwo-day postoperative recovery period, all S's were given four practice sessions in the shuttle box followed by one testing session with the current set at $30 \mu \mathrm{A} \mathrm{rms}$. On the practice sessions, as well as the testing session, food pellets were scattered over the floor of the stimulated side of the box.

Following the shuttle box experiment the $s^{\prime} s$ were tested for eating, drinking, and self-stimulation in the Skinner box. The procedures followed were identical with those of the first experiment. Thirty of these S's were tested for eating and 
drinking in a situation in which they had no control over the delivery of stimulation. Each $\mathrm{S}$ received 0.87 seconds of $30 \mu \mathrm{A}$ rms. stimulation every 30 seconds (programmed stimulation) during a half-hour testing session in the Skinner box with the bar disconnected from the stimulator.

Eight S's were subsequently tested in the two-bar Skinner box. The S's that appeared to press the food bar for food were also tested with the stimulation off, and in some cases the effect of programmed stimulation on bar-pressing for food was investigated.

Results

Mapping of Self-Stimulation Points

Histology was completed on 30 of the 46 animals. The histology was unsuccessful for six S's and testing was not completed in 10 animals because of sickness or loss of the electrode assembly.

Fig. 2 illustrates the electrode placements for the $30 \mathrm{~S}$ 's studied in this experiment and for 12 of the S's on which histology was completed in the first experiment. For the mapping of these points it was 
decided to use a system of classification that would distinguish between animals that bar-pressed at relatively fast rates and others that seemed less motivated. Each $S$ was placed in one of four groups on the basis of the average bar-pressing rate during the first two experimental sessions in the Skinner box. Table 5 illustrates the selection criteria used and the number of S's in each group.

Although self-stimulation was observed from all hippocampal regions, the effect was more pronounced in some areas than in others. High rates of bar-pressing were consistently found from placements in the dorsolateral hippocampus, the far anterior region of the hippocampus and the fimbria. The self-stimulation rate at medial placements, on the other hand, was more moderate, while self-stimulation by $S$ 's with electrodes in the dentate gyrus was customarily at very low rates. (The electrode tip was assumed to lie in the dentate gyrus only if it was below the hippocampal fissure but above the layer of molecular cells of the dentate gyrus. The pyramidal-ce11 layers of hippocampal fields $C A 3$ and CA 4 Iie directly below the molecular cells and it is, 


\begin{tabular}{lrrrr} 
Group & N & \multicolumn{2}{c}{ Bar-Pressing Rates } \\
1 & 7 & 0 & - & 5 \\
2 & 9 & 6 & - & 25 \\
3 & 4 & 26 & - & 50 \\
4 & 22 & 51 & - & 200 \\
& & & & \\
Tota1 & 42 & & &
\end{tabular}

Table 5. Criteria for classification of four groups of animals on the basis of rate of bar-pressing for stimulation. 
therefore, 1ikely that stimulation at a point below the molecular cells would affect these fields primarily.) There are insufficient data to make any definitive statements on the self-stimulation of S's with electrodes located in the ventral hippocampus. Histology was completed for only two S's with ventral placements; one had not learned to self-stimulate and the othex was categorized in Group 2. However, one S with an electrode aimed at the ventral hippocampus learned to self-stimulate at a very high rate. Although the histology for this $S$ was lost, both its behavioral response to stimulation and EEG records obtained from the electrode suggested that the electrode tip was, in fact, in the hippocampus. It seems, therefore, that there might be regional differences within the ventral hippocampus as there are within the dorsal. Mapping of Effects of Stimulation on Feeding

Since S's habituated to the Skinner box will customarily eat there with or without stimulation, it was necessary to establish a cut-off point above which the amount eaten may be taken as representing an increase due to stimulation. It was also useful to distinguish 
between animals which showed a slight facilitation of feeding and others for whom this facilitation was more marked. Each S was, therefore, placed in one of four groups. The criteria used for classification and the number of animals falling into each category is illustrated in Table 6. The range selected for Group 1. (non-eaters) was based on the consumption of the animals during the no-stimulation session. A frequency histogram of these scores is shown in Fig. 3. It can be seen that $89.7 \%$ of the scores during the control condition were less than 1.25 grams. Conversely, $10.3 \%$ of the animals ate over 1.25 grams during the control session. This means that the probability of an animal being erroneuusly classified as an eater is about one in ten according to the criteria used.

A difficulty in the determination of stimulationinduced feeding is that some S's did not self-stimulate and others did so at a rate which was probably too low to cause much eating. However, it was found that eating could be elicited using stimulation administered at regular intervals under the experimenters contro1. The score obtained during programmed stimulation was, 


\begin{tabular}{lrcrr} 
Group & N & \multicolumn{3}{c}{ Food intake } \\
(gm) \\
1 & 21 & 0 & - & 1.25 \\
2 & 4 & 1.26 & - & 1.74 \\
3 & 4 & 1.75 & - & 2.49 \\
4 & 11 & 2.50 & - & 5.00
\end{tabular}

Total 40

Table 6. Criteria for classification of four groups of animals on the basis of food intake during the session with hippocampal stimulation. 
therefore, used in evaluating the effect of hippocampal stimulation on feeding for all S's which either did not bar-press or had a low rate of bar-pressing (Groups 1 and 2, Table 5).

To determine the effects of programmed stimulation on eating, a comparison was made between the effects of self-stimulation and programmed stimulation on feeding for 20 animals, all of which were classified as selfstimulators. Of these 20, 12 were classified as eaters according to the criteria discussed above. The mean food intake for the two groups of S's under three different conditions is shown in Table 7. The animals classified as eaters ate significantly more during the session with programmed stimulation than on the session with no stimulation ( $t$-test for the difference between two correlated means, $d f=11 ; t=4.97 ; p<.001)$. The non-eaters, however, did not differ significantly under the two conditions $(d f=7 ; t=1.59 ; p>.10)$. It was therefore concluded that the animals which eat while self-stimulating also eat during programmed stimulation. On the other hand, animals which do not eat during self-stimulation do not eat during programmed stimulation 
No Stimulation

Eaters

$(\mathrm{N}=12)$

Non Eaters $(\mathrm{N}=8)$
1.11

1.02
Self-Stimulation

2.74

0.35

Programmed Stimulation

2.33

0.62

Table 7. Mean food intake during three conditions for two groups of animals, all categorized as self-stimulators. 
either.

A mapping of all the points studied and the category into which each falls is shown in Fig. 4. (This includes data for those $S$ 's that learned to selfstimulate in the first experiment. Excluded are animals which did not learn to self-stimulate and were not tested during programmed stimulation). Eating was not observed following stimulation of the anterior-dorsal hippocampus, the dentate gyrus, and the ventral hippocampus. This finding suggests that there is at least some degree of localization of function within the hippocampus.

Eating was observed occasionally following stimulation of the dorso-medial hippocampus and of the fimbria. Stimulation of the dorso-lateral hippocampus and the far anterior region of the hippocampus customarily induced large amounts of feeding. These results suggest that there may be more than one hippocampal region involved with the neural regulation of food intake. Effect of Hippocampal Stimulation on Drinking Behavior Of all the animals tested, only three were observed to drink more than one ml. of water during the session when food was not avallable. The electrode 
points for all three S's were lateral to the midline and in the posterior region of the dorsal hippocampus. While the similarity in anatomical location may imply that the drinking effect is restricted to a small circumscribed'region of the hippocampus, the proportionately low number of S's exhibiting the drinking makes it impossible to rule out chance variation as accounting for this finding. In any case, all three of the animals drank more than one $\mathrm{ml}$. of water during the no-stimulation session which eliminates the necessity of assuming that the drinking behavior was facilitated by the stimulation. Behavior of S's in the Two-Bar Skinner Box

The findings of this experiment generally confirm the findings of the first experiment, although there were some peculiarities which may be attributable to electrode placements, Fig.5 shows a leaxning curve for one $S$. For this animal, comparisons between the rates of barpressing for food during conditions of self-stimulation, programmed stimulation and no stimulation clearly indicate the importance of hippocampal stimulation on the motivation to press for food. Two S's did not learn to press for food under the Initial conditions, but 
they learned the response after being put on a fooddeprivation schedule. These animals subsequently barpressed for food during hippocampal self-stimulation when they were satiated, but pressed at a far lower rate when the stimulator was off.

Three animals learned to press for food during hippocampal stimulation. However, in the case of one of these animals this response disappeared on subsequent testing, while the other two animals pressed as frequently during extinction as they had while self-stimulating. This result is perplexing, but may have been artifactual since these S's were given only one extinction session. Two other animals (one of which was not originally classified as an eater) did not learn to press for food either during the initial self-stimulation conditions or after being placed on a food-deprivation schedule.

The placements most effective for motivating learning of the food-reinforced response were those in the dorso-lateral hippocampus, Clear indications of learning were absent in two S's with electrodes in the dorso-medial hippocampus and one animal with a far-anterior placement. 
Behavior of S's in the Shuttle Box Experiment

To discover more about the significance of the shuttle box results, the scores obtained were correlated with the bar-pressing rates of the same animals in the Skinner box. (The correlations are based on $37 \mathrm{~S}$ 's. This includes all animals which were tested in this experiment in both the shuttle box and Skinner box, regardless of whether histology was obtained.)

The rank-order correlation (Spearman's $\rho$ ) between bar-pressing rate in the Skinner box and crossover rate in the shuttle box is highly significant $(P=.668 ; t=4.27 ; \mathrm{df}=36 ; \mathrm{p}<.001)$. The correlation between bar-pressing rate and total stimulation is also significant $(p=.40 ; d f=36 ; t=2.79 ; p<.01)$. These results indicate that stimulation in the shuttle box is positively reinforcing as it is in the Skinner box. The difference in the correlation coefficients, however, suggests that the crossover score is a better predictor of bar-pressing behavior than is the totalstimulation score.

As in the first experiment, there was 1ittle 
evidence of facilitated eating in the shuttle box. Significant eating was seen in only two animals, both of which also ate during self-stimulation in the Skinner box experiment. It may be important that the two animals had electrodes located in the same region, the dorso-medial hippocampus. No definite anatomical conclusions can be made, however, since other animals with electrodes in the dorso-medial hippocampus did not show this effect.

\section{EXPERIMENT III}

This experiment was a preliminary attempt to assess the importance of the hippocampal projection pathways in food regulation. According to Raisman, Cowan and Powe11 (1966), there are two primary efferent hippocampal pathways. Axons from the anterior and medial region of the hippocampal pyramidal field CA 1 are thought to turn medially into the dorsal fornix which runs dorso-medially into the fornix bodies. Axons from the other pyramidal cell region leave the hippocampus by way of the fimbria. Although the fimbria and dorsal fornix meet in the precommissural fornix, it is thought 
that they project to different regions. The findings of the second experiment suggest that the fimbria is more important in food regulation. Direct stimulation of the fimbria was found to cause eating, and stimulation at points 1ikely to project to the dorsal fornix were customarily without effect. Although these findings imply that the hippocampal system involved with feeding includes only the fimbria, another pathway (e.g., the temperoammonic tract) could also be important even though little anatomical evidence is consistent with this interpretation. It is also possible that hippocampal stimulation induces a change independent of neural transmission, which somehow leads to feeding. To help distinguish between these alternatives, an attempt was made to determine the effects of fimbria cuts on the subsequent elicitation of both hippocampal self-stimulation and feeding following the stimulation. Subjects

Seven male hooded rats served as subjects in this experiment. All S's underwent a two stage operation. They were first implanted with electrodes at points which had previously been found effective in 
the elicitation of both self-stimulation and feeding. Bilateral cuts of the fimbria were made approximately two weeks later as described earlier.

$\underline{\text { Procedure }}$

A1though a11 of the S's in this experiment learned to self-stimulate and were classified as eaters, the eating was not always immediately manifest. Typical curves of the amounts eaten (Fig. 6) illustrate daily increases until an asymptote is reached. After a number of sessions, some animals ate more than was observed in any animals in the previous experiments. Fig. 7 shows the approximate location of the electrode tips for all seven S's. The mean food intake for three S's (numbers $81,87 \& 90$ ) was exceptiona11y high (see Table 8). A11 three S's reached an asymptote of over five grams of food; two of these animals occasionally ate over seven grams of food during the half-hour testing sessions. It is of interest that the electrode tips of all three animals were in approximately the same location, the far-lateral pyramidal cell layer (Field $\mathrm{Ca} 3$ ) of the dorsal-1ateral hippocampus . 


\begin{tabular}{lcccc} 
& \multicolumn{2}{c}{ Pre-op } & \multicolumn{2}{c}{ Post-op } \\
Subject & $\begin{array}{c}\text { Mean Food } \\
\text { Intake } \\
(\mathrm{gm})\end{array}$ & $\begin{array}{c}\text { Mean Bar- } \\
\text { Presses }\end{array}$ & $\begin{array}{c}\text { Mean Food } \\
\text { Intake } \\
\text { (gm) }\end{array}$ & $\begin{array}{c}\text { Mean Bar- } \\
\text { Presses }\end{array}$ \\
81 & 2.23 & 125 & 5.15 & 113 \\
82 & 2.50 & 67 & 1.94 & 77 \\
84 & 2.04 & 67 & 2.05 & 45 \\
85 & 2.62 & 31 & 2.91 & 53 \\
87 & 4.21 & 75 & 5.55 & 177 \\
88 & 2.08 & 45 & 2.39 & 38 \\
90 & 6.53 & 121 & 5.76 & 124
\end{tabular}

Table 8. Mean food intake and mean self-stimulation rate for seven subjects on three preoperative and three postoperative testing sessions. (The postoperative testing sessions were on days two, three and four after the operation.) 
Representative lesions are illustrated in Fig. 8. In no case was the fimbria completely sectioned, though the lesion of number 84 spared only the farlateral regions. Two S's, numbers 85 and 90 , sustained complete sections of the dorsal fornix; two other S's, numbers 81 and 88 , had large but subtotal destruction of this area. The lesions in the other two animals did not extend below the corpus callosum.

On inspection of Table 8 it is clear that the lesions did not cause a significant decrement in the response for hippocampal stimulation or in the amount of stimulation induced eating. The marked postoperative increase in eating of one $S$ (number 81) is probably not a lesion effect since this increase was not seen in other animals with similar lesions. No definite conclusions on the functional importance of the fimbria can be arrived at since fimbrial cuts were not complete. However, the lack of any decrement in S's sustaining complete resection of the dorsal fornix seems to rule out this pathway as being significant in the eating induced by hippocampal stimulation. 
Discussion

It was originally hoped that some of the lesions would at least partially spare the fimbria, while others would completely section this fiber path. It would then have been possible to dissociate the effects of lesions of the fimbria from those of the dorsal fornix. In the absence of any complete fimbrial sections, it is possible to conclude only that cuts of the dorsal fornix are without effect. Nevertheless, some of the findings in this experiment help to clarify the anatomical localization of eating induced by hippocampa1 stimulation.

In the second experiment it was noted that hippocampal stimulation caused different amounts of eating in different subjects. The eating observed in some animals could, therefore, have been caused by the spread of current to neighboring hippocampal regions rather than by direct excitation of the cells at the electrode tip. If this is correct it might be expected that there would be a critical region of the hippocampus which when stimulated would cause the most vigorous eating. The exceptional eating observed in three S's 
supports this argument and suggests that the critical region may be the far-lateral pyramidal cells in the medial region of the dorso-1ateral hippocampus. Furthermore, the amount of eating observed in the other four S'S was inversely correlated with the distance of the electrode tip from this region.

Mention should also be made of the daily increases in feeding noted on the first few testing sessions (see Fig. 6). The amount of feeding induced by hippocampal stimulation apparently increases with repeated experience with the stimulation. This phenomenon is reminiscent of the behavior of normal rats on a fooddeprivation schedule. Baker (1955) found increases in feeding up to ten days after rats were first deprived of food. The effect of experience on feeding elicited by hippocampal stimulation, therefore, demonstrates another similarity between normal hunger and the hunger induced by hippocampal stimulation. 


\section{GENERAL DISCUSSION}

The most important finding of these studies is the facilitated eating seen in animals bar-pressing for hippocampal stimulation in the Skinner box. This effect was clearly caused by the stimulation, not by lesions produced during the operation or other artifactual causes. Increased eating, however, was not seen in the shuttle box although the animals apparently found the stimulation reinforcing in this apparatus also. In the shuttle box, food was placed on the stimulated side of the box and, consequently, was available only while the animals were receiving stimulation. In the Skinner box, however, it was necessary for the animals to release the bar (thus turning the stimulation off) in order to obtain the food. The implication of these differences is that the feeding was caused by an aftereffect of the stimulation, not by the stimulation itself. It is, therefore, necessary to consider the nature of this aftereffect in order to account for the findings of the present investigation. One possibility is that the aftereffect of hippocampal stimulation results from sustained afterdischarge activity. It is well known that such activity is easily 
elicited by brief hippocampal stimulation. After the stimulation is turned off, hippocampal afterdischarge frequent1y continues for approximately 20 seconds, (MacLean, 1957); a time period similar to that for the feeding seen in the present investigation. Although it is not clear why afterdischarge activity should be related to feeding, Green (1964) has pointed out that the spread of hippocampal afterdischarge to other structures is not necessarily on the basis of established anatomical connections. It might, therefore, be argued that the feeding is caused by remote excitation of another neural region.

It is, however, unlikely that afterdischarge activity is responsible for the feeding reported in my experiments. Such an explanation would not readily account for the anatomical localization of function demonstrated in the second experiment. Furthermore, the procedure followed was such as to make it unlikely that afterdischarge was evoked by each stimulation. In two animals which were found to eat reliably following hippocampal stimulation, I recorded the hippocampal activity evoked by a one-second stimulation of $30 \mu \mathrm{A}$ 
intensity delivered once every thirty seconds during a half-hour testing session. Afterdischarge was seen after the first or second stimulation only. Eating was not observed during hippocampal afterdischarge, but the animals ate following almost every other stimulation. If the aftereffect of hippocampal stimulation which causes eating is not sustained afterdischarge, what then is it? The evidence relating to this question is mainly indirect and stems from some behavioral differences between animals in the shuttle box and those in the Skinner box.

In both the first and second experiments it was found that animals spent a considerable time on the stimulated side in the shuttle box. While receiving this stimulation they were usually inactive. In the Skinner box, the animals delivered much shorter bursts of stimulation, immediately after which they became hyperactive. My evidence, therefore, suggests that hippocampal stimulation is behaviorally inhibitory but the aftereffect of the stimulation is excitatory. The inhibitory effect of direct hippocampal stimulation seems to be well substantiated by previous research. 
For example, Kaada, Jansen and Andersen (1953) reported that al1 spontaneous behaviors ceased with the onset of hippocampal stimulation.

Although the excitatory aftereffect of hippocampal stimulation has received little previous study, there is evidence consistent with this interpretation. Maclean (1957) reported that there were enhanced pleasure reactions following the recovery from chemically or electrically induced hippocampal seizure activity in cats; these were characterized by grooming, purring, and general approach behavior. Also with cats, Delgado and Sevillano (1961) observed what appeared to be hyperactivity after the termination of hippocampal afterdischarge. Finally, Cazard and Buser (1963) found that attentive searching behavior was occasionally manifest a few seconds after the termination of non-epileptogenic stimulation in rabbits. Although the specific behavioral descriptions vary, they all suggest that increases in general activity occur during the aftereffect of hippocampal stimulation.

The function of the hippocampus in behavioral arousal has also been a frequent theme in studies of 
animals with hippocampal lesions. Such animals are reported to be hyperactive (e.g., Milner \& Teitelbaum, 1963) and hyperreactive (e.g., Kamback, 1967). Thus, both the aftereffect of hippocampal stimulation and hippocampal lesions cause increased activity; hippocampal stimulation has on opposite effect. These findings suggest that the aftereffect of the stimulation is a decrease in hippocampal activity. It also seems reasonable that the aftereffect of the stimulation would be opposite to the effects of the stimulation. The neural activity, elicited by brain stimulation, is likely to be temporarily fatigued after the stimulation is turned off (except in the case of an afterdischarge in which case the hypoactivity will follow the afterdischarge).

Assuming that the aftereffect of hippocampal stimulation correlates with decreased neural activity, then my results imply that the hippocampus is involved in the modulation, rather than the direct initiation, of feeding. It is therefore suggested that the hippocampus normally functions to inhibit a motivational system which, when active, causes feeding, and that the 
feeding system is disinhibited during the aftereffect of hippocampal stimulation. This disinhibition serves either to sensitize the feeding system so that it is more readily excited by relevant sensory input (food) or to cause a rebound excitation of the feeding system. In either case, increased eating would be expected during the aftereffect of hippocampal stimulation. More explicitly, I am suggesting that hippocampal inhibition directly affects the lateral hypothalamic region which is thought to be important in the activation of feeding. The idea that the hippocampus modulates hypothalamic activity is consistent with the different temporal effects of stimulation of both structures on feeding. The feeding elicited by hypothalamic stimulation customarily begins with the onset of stimulation and ends abruptly when the stimulation is turned off (e.g., Miller, 1957). Eating induced by hippocampal stimulation, however, begins only after the stimulation is turned off. The anatomical connections of the hippocampus are consistent with this theory. The postcomissural fornix and the medial forebrain bundle both contain fibers which originate in the hippocampus 
and terminate in the lateral hypothalamic area (e.g., Nauta, 1958; Raisman, Cowan \& Powe11, 1966).

A1though there is no direct evidence that hippocampal stimulation inhibits the lateral hypothalamic area involved with feeding, such a relationship is indirectly suggested by some recent studies. Siegal and Flynn (1967) reported that concurrent stimulation of the dorsal hippocampus suppresses the attack elicited by hypothalamic stimulation in cats. Using rats, Hansen (1966) found that concurrent hippocampal stimulation substantially reduces the rate of bar-pressing for hypothalamic stimulation. Hippocampal lesions, on the other hand, have been found to increase the bar-pressing rate for hypothalamic stimulation (Asdourian, Stutz \& Rocklin, 1966; Jackson, 1967). In Jackson's study, the bar-pressing rate was also increased by food deprivation when the animals were tested preoperatively; food deprivation had no additional postoperative effects. Thus far, the discussion has been limited to the function of the hippocampus in feeding. The hippocampus also seems to be important in the control over other behaviors. Increased drinking has been 
reported following both chemical stimulation of the hippocampus (Fisher \& Coury, 1962) and hippocampal lesions (Kimble \& Coover, 1966). Sexual behavior is facilitated during the aftereffect of hippocampal stimulation (Maclean, 1958) and as a result of hippocampal lesions (Bermant, Glickman, \& Davidson, 1968; Kim, 1960). Finally, hippocampal lesions disrupt maternal behavior (Kimble, Rogers, \& Hendrickson, 1967). The function of the hippocampus in these behaviors appears to be similar to that previous1y suggested in feeding. Hippocampal lesions (at least in the case of drinking and sexual behavior) produce a facilitation of the behavior reported; this would be expected if an inhibitory control mechanism were removed. An important similarity between feeding, drinking, sexual activity and maternal behavior is that they can all be classified as biologically primitive (Hebb, 1966), is., they are necessary for the continued existence of either the individual or the species. The idea that the hippocampus is involved in the control of biologically primitive behaviors is not new (e.g., Maclean, 1958). I wish to suggest that 
the hippocampus is involved, specifically, in the modulation of these behaviors by means of neural inhibition and that there is a separation of function of the elements within the hippocampus which are involved in these different behaviors. (This is in contrast to the proposal that the hippocampus exerts a non-specific modulatory effect over all motivational behaviors, Nade1, 1967).

It is not yet clear whether the separation of function within the hippocampus is based on anatomical or biochemical factors. My findings indicate that the hippocampal elements involved in feeding are anatomically organized. Coury (1967) has presented evidence which also supports this conclusion, although the crucial area for eliciting feeding with adrenergic stimulation is apparently different from the crucial region for eliciting feeding with electrical stimulation. Fisher and Coury (1962) have found that drinking can be elicited by cholinergic stimulation of certain hippocampal regions only.

The studies using chemical stimulation of the brain also indicate that the hippocampal elements involved 
in feeding and drinking are chemically coded (e.g., Coury, 1967). Some indirect evidence suggest that hippocampal units are selectively sensitive to sexual hormones (Kawakami, Seto, \& Terasawa/, 1967).

The available evidence therefore seems to indicate that there is both an anatomical and a chemical basis for the separation of function of the hippocampal elements which modulate different behaviors. From this viewpoint, the failure to obtain any stimulation-induced facilitation of drinking may be more understandable. Electrical stimulation may have a more selective effect than is usually thought. It is also possible that feeding and drinking are separated only chemically and that eating overrides drinking when the system is stimulated electrically.

Some investigators have considered exploratory behavior as biologically primitive (e.g., Hebb, 1966). Strictly defined, exploration refers to the behavioral response to novel stimulation (Bindra, 1959). However, the term is sometimes used more 1oosely to apply to locomotor activity in general. The evidence, previously mentioned, on the activity changes resulting from either 
hippocampal stimulation or hippocampal lesions indicates that the hippocampus is involved in exploration (at least in the wider meaning of the word). Since hippocampal lesions and the aftereffect of hippocampal stimulation both cause increases in exploration, the hippocampus seems to have a modulatory function in this behavior also.

In the present investigation, increased activity was seen during the aftereffect of hippocampal stimulation in all animals tested. This observation appears to contradict the argument that within the hippocampus there is some degree of anatomical localization of function. Furthermore, it is unlikely that there were qualitative differences in the activation produced by stimulation of different regions. In the absence of food, the behavioral response of the animals with different placements seemed indistinguishable.

The increased activity seen during the aftereffect of dorso-lateral hippocampal stimulation may represent food-seeking. Thus, although the overt activity produced by the aftereffect of the stimulation may be identical with different electrode placements, the causes 
of this activity may differ. This suggestion is supported by the finding that animals will feed following stimulation at certain hippocampal placements if the S's are able to find the food. It can also be argued that the lack of any consummatory behavior following stimulation at other placements resulted from the absence of the appropriate goal object (Glickman \& Shiff, 1967). Implicit in this argument is the assumption that food-seeking is a specific type of goal-directed behavior and consequently differs from exploration. This assumption is warranted when animals perform a learned response for food. In the absence of learning, however, a distinction between food-seeking and exploration is unjustified. The urge for food is but one of many factors which can facilitate or initiate exploratory activity.

From this viewpoint, exploration is related to, but different from, the other behaviors discussed. Correspondingly, the function of the hippocampus in exploratory behavior seems different from its function in feeding. An interesting possibility is that the hippocampus contains two distinct systems; one, which has previously been discussed, is involved in the 
control of biologically primitive behaviors, the other is involved primarily with behavioral activation (exploration). Interaction between these two systems allows for food deprivation, for example, to influence exploration.

Some studies of animals with selective hippocampal lesions suggest that the system involved in exploration is more medially located. Lesions restricted to the medial region of the dorsal hippocampus are reported to cause increased activity (Lynch \& Campbe11, 1968), while lesions restricted to the lateral region have no effect on activity (Green, Beatty \& Schwartzbaum, 1967; Lynch \& Campbe11, 1968). Complete removal of the dorsal hippocampus also causes increased activity (e.g., Green, Beatty \& Schwartzbaum, 1967). In such animals, the effect is greatly potentiated by food deprivation (Lynch \& Campbe11, 1968; Schmaltz \& Isaacson, 1967). The activity changes resulting from restricted damage to the medial region, however, are not affected by fooddeprivation (Lynch \& Campbe11, 1968). Thus, the medial region seems to be important in controlling exploration while the lateral region seems to be involved in 
controlling the influence of food deprivation or exploration.

A final topic deserves consideration. The major technique used in my experiments were selfstimulation. All but one of the animals which ate also learned to self-stimulate. Hippocampal stimulation, therefore, not only induced feeding, but was positively reinforcing. This finding is consistent with the present theoretical framework. It is known that lateralhypothalamic stimulation elicits stimulus-bound eating and is positively reinforcing (Hoebel \& Teitelbaum, 1962; Margules \& 01ds, 1962). If the aftereffect of hippocampal stimulation causes lateral-hypothalamic excitation, this might be basis of the reinforcement that maintains the hippocampal self-stimulation.

The differences in the bar-pressing behavior of animals with lateral-hypothalamic electrodes (who press persistently) and animals with hippocampal electrodes (who press infrequently, but reliably) does not argue against this viewpoint. The aftereffect of hippocampal stimulation is long-lasting. Thus, a brief hippocampal stimulation may lead to sustained hypothamic 
excitation. The excitatory effect of hypothalamic stimulation, however, does not outlast the delivery of the stimulation.

The suggestion that hippocampal stimulation is positively reinforcing for the same reason as lateralhypothalamic stimulation requires an explanation of hypothalamic self-stimulation. On the other hand, hippocampal self-stimulation may prove a useful means of furthering the understanding of hypothalamic selfstimulation. 


\section{SUMMARY}

The role of the hippocampus in the neural regulation of feeding behavior was examined in three experiments. A significant increase in feeding behavior was seen in animals bar-pressing for hippocampal stimulation when the electrode was located in the dorso-lateral hippocampus. This effect was not observed in animals with electrodes in the inedial cortical region, the dentate gyrus, the ventral hippocampus, and the anterior region of the dorsal hippocampus. Lesions of the dorsal fornix did not affect the feeding elicited by dorso-lateral hippocampal stimulation.

The feeding seen in these experiments was caused by an aftereffect of the stimulation. This aftereffect is probably decreased hippocampal activity, leading to the suggestion that the hippocampus serves a modulate feeding behavior. 


\section{REFERENCES}

Anand, B.K., and Brobeck, J.R. Hypothalamic control of food intake in rats and cats. Yale J. Biol. Med., $1951, \underline{24}, 123-140$.

Anand, B.K., and Brobeck, J.R. Food intake and spontaneous activity of rats with lesions in the amygdaloid nuclei. J. Neurophysiol., 1952, 15, 421-431.

Anand, B.K., and Dua, S. Feeding responses induced by electrical stimulation of the hypothalamus in cat. Ind. J. med. Res., 1955, 43, 113-122.

Anand, B.K., Dua, S., and Singh, B. Electrical activity of the hypothalamic "feeding centres" under the effect of changes in blood chemistry. EEG clin. Neurophysio1., 1961, 13, 54-59.

Andersson, B., Gale, C.C., and Sundsten, J.W. Preoptic Influences on water intake. In M.J. Wayner (Ed.), Thirst. New York: Pergamon Press, 1964, Pp. 361-379. Andersson, B., and Larsson, B. Influence of local temperature changes in the preoptic area and rostral hypothalamus on the regulation of food and water intake. Acta physio1. Scand., 1961, 52, 79-89. 
Asdourian, D., Stutz, M.R., and Rock1in, K.W. Effects of thalamic and limbic system lesions on selfstimulation. J. comp. physio1. Psycho1., 1966, 61, 468-472.

Bailey, P., and Bremer, F. Experimental diabetes insipidus. Arch. int. Med., 1921, 28, 773-803. Baker, R.A. The effects of repeated deprivation experience on feeding behavior. J. comp. physiol. Psychol., 1955, 48, 37-42.

Bermant, G., Glickman, S.E., and Davidson, J.M. Effects of limbic lesions on copulatory behavior of male rats. J. comp. physiol. Psycho1., 1968, 65, 118-125. Bindra, D. Motivation: a systematic reinterpretation. New York: Ronald Press, 1959.

Brobeck, J.R. Food and temperature. Recent Progr. Hormone

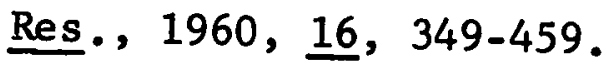

Brown, S., and Schaefer, E.A. An investigation into the functions of the occipital and temporal lobes of the monkey's brain. Phil. Trans. roy. Soc. London, 1888, 179, 303-327.

Brügger, M. Fresstrieb als hypothalmisches Symptom. Helv. physio1. pharmacol. Acta, 1943, 1, 183-198. 
Cazard, M.B., and Buser, P. Modification des reponses sensorielles corticales par stimulation de 1 'hippocampe dorsal chez le lapin. EEG clin. Neurophysiol., 1963, 15, 413-425.

Coons, E.E., Levak, M., and Miller, N.E. Lateral hypothalamus: learning of food-seeking response motivated by electrical stimulation. Science, 1965, 150, $1320-1321$.

Corbit, J.D. Hyperphagic hyperreactivity to adulteration of drinking water with quinine $\mathrm{HCl}$. J. comp. physiol. Psycho1., 1965, 60, 123-124.

Coury, J.N. Neural correlates of food and water intake in the rat. Science, $1967, \underline{156}, 1763-1765$.

Covian, M.R. Studies on the neurovegetative and behavioral functions of the brain septal area. Progr. Brain Res., $1967,27,189-217$.

Crosby, E.C., Humphrey, T., and Lauer, E.W. Correlative anatomy of the nervous system. New York, Macmillan, 1962.

Davis, J.D., Gallagher, R.L., and Ladove, R. Food intake controlled by a blood factor. Science, 1967, 156, 1247-1248. 
Delgado, J.M.R., and Sevillano, M. Evolution of repeated hippocampal seizures in the cat. EEG.clin. Neurophysiol., 1961, 13, 722-733.

Deutsch, J.A., and Deutsch, D. Physiological Psychology. Homewood, I11inois. The Dorsey Press, 1966. Ellen, P., and Powe11, E.W. Temporal discrimination in rats with rhinencephalic lesions. Exp. Neurol., $1962, \underline{6}, 538-547$.

Ehrlich, A. Effects of tegmental lesions on motivated behavior in rats. J. comp. physiol. Psycho1., 1963, $\underline{56}, 390-396$.

Epstein, A.N. Reciprocal changes in feeding behavior produced by intra-hypothalamic chemical injections. Amer. J. Physiol., 1960, 199, 969-974.

Fisher, A.E., and Coury, J.N. Cholinergic tracing of a central neural circuit underlying the thirst drive. Science, $1962, \underline{138}, 691-693$.

Fisher, A.E., and Coury, J.N. Chemical tracing of neural pathways mediating the thirst drive. In M.J. Wayner (Ed.), Thirst. New York: Pergamon Press, 1964, Pp. 515-529. 
Fonberg, E., and Delgado, J.M.R. Avoidance and alimentary reactions during amygdaloid stimulation. J. Neurophysio1., 1961, 24, 651-664.

Glickman, S.E., and Schiff, B.B. A biological theory of reinforcement. Psycho1. Rev., 1967, 74, 81-109. Green, J.D. The hippocampus. Physiol. Rev., 1964, 44, 561-608.

Green, J.D., Clemente, C.D., and De Groot, J. Rhinencephalic lesions and behavior in cats. An analysis of the Kluver Bucy syndrome with particular reference to normal and abnormal sexual behavior. J. comp. Neurol., $1957,108,505-545$.

Green, R.H., Beatty, W.W., and Schwartzbaum, J.S. Comparative effects of septo-hippocampal and caudate lesions on avoidance behavior in rats. J. comp. physio1. Psychol., 1967, 64, 442-452.

Grossman, S.P. Eating and drinking elicited by direct adrenergic or cholinergic stimulation of the hypothal amus. Science, 1960, 132, 301-302.

Grossman, S.P. Behavioral effects of chemical stimulation of the ventral amygdala. J. comp. physiol. Psychol., 1964, 57, 29-36. 
Grossman, S.P. The VMH: a center for affective reactions, satiety, or both: Physiol. Behav., 1966, 1, 1-10.

Grossman, S.P. A textbook of physiological psychology.

New York: John Wiley \& Sons, 1967.

Grossman, S.P., and Grossman, L. Food and water intake following lesions or electrical stimulation of the amygdala. Amer. J. Physiol., 1963, 205, 761-765.

Hamilton, C.L. Control of food intake. In W.S. Yamamoto and J.R. Brobeck (Eds.), Physiological controls and regulations. Philadelphia: W.B. Saunders Co., 1965, Pp. 274-294.

Hamilton, C.L., and Brobeck, J.R. Hypothalamic hyperphagia in the monkey. J. comp. physio1. Psychol., 1964a, 57, 271-278.

Hamilton, C.L., and Brobeck, J.R. Food intake and temperature regulation in rats with rostral hypothalamic lesions. Amer. J. Physiol., 1964b, 207, 291-297.

Hansen, E. Relation of hippocampal activity to hypothalamic rewarding stimulation. Unpublished M. Sc. Thesis, McGill University, 1966. 
Hebb, D.0. A textbook of Psychology. Philadelphia:

W.B. Saunders Co., 1966.

Hernández-Peón, R., Chávez-Ibarra, G., Morgane, P.J., and Timo-Iaria, C. Limbic cholinergic pathways involved in sleep and emotional behavior. Expt. Neuro1., 1963, $8,93-111$.

Hetherington, A.W. Non-production of hypothalamic obesity in the rat by lesions rostral or dorsal to the ventro-medial hypothalamic nuclei. J. comp. Neurol., 1944, 80, 33-45.

Hetherington, A.W., and Ranson, S.W. Hypothalamic lesions and adiposity in the rat. Anat. Rec., 1940, 78, $149-172$

Hoebel, B.G. Hypothalamic lesions by electrocauterization: disinhibition of feeding and self-stimulation. Science, $1965, \underline{149}, 452-453$.

Hoebel, B.G., and Teitelbaum, P. Hypothalamic control of feeding and self-stimulation. Science, 1962, $135,375-376$.

Jackson, F. The effects of posterior hippocampal lesions upon intracranial self-stimulation rates under satiation and deprivation conditions. Unpublished $\mathrm{Ph}$.D. Thesis, Rutgers University, 1967. 
Kaada, B.R., Jansen, J. Jr., and Andersen, P. Stimulation of the hippocampus and medial cortical areas in unanesthetized cats. Neurology, 1953, $\underline{3}, 844-857$.

Kamback, M. Effect of hippocampal lesions and food deprivation on response for stimulus change. J. comp. physio1. Psycho1., 1967, 63, 231-235.

Kawakami, M., Seto, K., Terasawa, E., and Yoshida, K. Mechanisms in the limbic system controlling reproductive functions of the ovary with special reference to the positive feedback of progestin to the hippocampus. Progr. Brain Res., 1967, 27, 69-102.

Kim, C. Sexual activity of male rats following ablation of hippocampus. J. comp. physiol. Psychol., 1960, $\underline{53}, 553-557$.

Kimble, D.P., and Coover, G.D. Effect of hippocampal lesions on food and water consumption in rats. Psychon. Sci., 1966, 4, 91-92.

Kimble, D.P., Rogers, L., and Hendrickson, C.W. Hippocampal lesions disrupt maternal, not sexual behavior in the albino rat. J. comp. physio1. Psychol., 1967, $\underline{63}, 401-407$. 
Klüver, $\mathrm{H}_{\text {, }}$, and Bucy, P.C. Preliminary analys is of functions of the temporal lobes of monkeys. Arch. Neurol. Psychiat., 1939, 42, 979-1000.

Kohn, M. Satiation of hunger from food injected directly into the stomach versus food ingested by mouth. J. comp. physio1. Psychol., 1951, 44, 412-422.

Krasne, F.B. General disruption resulting from electrical stimulation of the ventromedial hypothalamus. Science, 1962, 138, 822-823.

Larsson, S. On the hypothalamic organization of the nervous mechanism regulating food intake. Acta. physio1. Scand., 1954, 32, Supp1.115, 1-63.

Lynch, G.S., and Campbe11, B.A. Effects of discrete and gross hippocampal lesions on spontaneous activity during ad-libitum and food deprivation conditions. Paper read at Eastern Psychological Association Meeting, Washington, 1968.

MacLean, P.D. Psychosomatic disease and the "visceral brain". Recent developments bearing on the Papez theory of emotion. Psychosom. Med., 1949, 11, 338-353. 
MacLean, P.D. Chemical and electrical stimulation of the hippocampus in unrestrained animals. 11 behavioral findings. Arch. Neurol. Psychiat., $19.57, \underline{78}, 113-127$.

MacLean, P.D. The limbic system with respect to self-preservation and the preservation of the species. J. nerv, ment. Dis., 1958, 127, 1-11. Maire, F.W. Eating and drinking responses elicited by diencephalic stimulation in unanesthetized rats. Fed. Proc., 1956, 15, 124.

Margules, D.L., and 01ds, J. Identica1 "feeding" and "rewarding" systems in the 1ateral hypothalamus of rats. Science, $1962,135,374-375$.

Mayer, J. Glucostatic mechanism of regulation of food intake. New Eng1. med. J., 1953, 249, 13-16. Miller, N.E. Experiments on motivation. Science, 1957, 126, $1271-1278$.

Miller, N.E. Implications for theories of reinforcement. In D.E. Sheer (Ed.), Electrical stimulation of the brain. Austin: Univer. Texas Press, 1963, Pp. 575-581. Morgane, P.J. Medial forebrain bundle and "feeding centers" of the hypothalamus. J. comp. Neuro1., 1961a, 117,1-25. 
Morgane, P.J. Alterations in feeding and drinking behavior of rats with lesions in globi pallidi. Amer. J. Physio1., 1961b, 201, 420-428.

Morgane, P.J. Distinct "feeding" and "hunger motivating" systems in the lateral hypothalamus of the rat. Science, $1961 \mathrm{c}, \underline{133}, 887-888$.

Morgane, P.J. Limbic-hypothalamic-midbrain interaction in thirst and thirst motivated behavior. In M.J. Wayner (Ed.), Thirst. New York: Pergamon Press, 1964, Pp. 429-455.

Morgane, P.J. The role of the limbic-midbrain circuit, reticular formation, and hypothalamus in regulating food and water intake. In Proceedings of the seventh international congress of nutrition, Vol.II. Hamburg, 1966, Pp. 1-16.

Morgane, P.J., and Kosman, A.J. A rhinencephalic feeding center in the cat. Amer. J. Physiol., $1959,197,158-162$.

Morgane, P.J., and Kosman, A.J. Relationship of the middle hypothalamus to amygdala: hyperphagia. Amer. J. Physiol., 1960, 198, 1315-1318. 
Nade1, L. Behavioral effects of dorsal and ventral hippocampal lesions in the rat. Unpublished Ph.D. Thesis, McGill University, 1967.

Nauta, W.J.H. Hippocampal projections and related neural pathways to the mid-brain in the cat. Brain, 1958, 81, 319-340.

Niki, H. The effects of hippocampal ablation on the inhibitory control of operant behaviors in the rat. Jap. J. Psychol., 1965, I, 126-137.

O'Keefe, J. Response properties of amygdalar units in the freely moving cat. Unpublished Ph.D. thesis, McGill University, 1967.

OIds, J., and Milner, P. Positive reinforcement. produced by electrical stimulation of the septal area and other regions of the rat brain. J. comp. physio1. Psychol., 1954, 47, 419-427.

Oomora, Y., Ooyama, H., Yamamoto, T., Naka, F., Kobayashi, N., and Ono, T. Neuronal mechanisms of feeding. Progr. Brain Res., 1967, 27, 1-33.

Palmer, W.E., and Lash, L. Effects of hippocampectomy on food and water consumption and body weight in rats under ad $\underline{1 \mathrm{ib}}$. and deprivation feeding conditions. Paper read at Eastern Psychological Association Meeting, Washington, 1968. 
Papez, J.W. A proposed mechanism of emotion. Arch. Neuro1. Psychiat. 1937, 38, 725-743.

Parker, S.W., and Feldman, S.M. Effect of mesencephalic lesions on feeding behavior in rats. Expt. Neuro1., $1967,17,313-326$.

Pizzi, W.J., and Lorens, S.A. Effects of lesions in the amygda1o-hippocampo-septal system on food and water intake in the rat. Psychon. Sci., 1967, $\underline{7}$, $187-188$.

Pubols, L.M. Changes in food-motivated behavior of rats as a function of septal and amygdaloid lesions. Expt. Neuro1., 1966, 15, 240-254.

Raisman, G., Cowan, W.M., and Powell, T.P.S. An experimental analysis of the efferent projection of the hippocampus. Brain, 1966, $\underline{89}, 83-108$.

Raphelson, A.C., Isaacson, R.L., and Douglas, R.J. The effect of limbic damage on the retention and performance of a runway response. Neuropsychologia, $1966, \underline{4}, 253-264$.

Reynolds, R.W. Ventromedial hypothalamic lesions without hyperphagia. Amer. J. Physiol., 1963, 204, 60-62. 
Reynolds, R.W. An irritative hypothesis concerning the hypothalamic regulation of food intake. Psychol. Rev., 1965, 72, 105-116.

Roberts, W.W., Steinberg, M.L., and Means, L.W. Hypothalamic mechanisms for sexual, aggressive, and other motivational behaviors in the opossum, didelphis Virginians. J. comp. physio1. Psycho1., $1967,64,1-15$.

Robinson, B.W. Forebrain alimentary responses: some organizational principles. In M.J. Wayner (Ed.), Thirst. New York Pergamon Press, 1964, Pp. 411-427. Robinson, B.W., and Mishkin, M. Alimentary responses evoked from forebrain structures in Macaca mulatta. Science, 1962, 136, 260-261.

Rodgers, W.L., Epstein, A.N., and Teitelbaum, P. Lateral hypothalamic aphagia: motor control or motivational deficit? Amer. J. Physiol., 1965, 208, 334-342. Routtenberg, A. Drinking induced by carbachol: thirst circuit or ventricular modification? Science, $1967,157,838-839$. 
Routtenberg, A., and Kane, R.S. Weight loss following lesions at the self-stimulation point: ventral midbrain tegmentum. Canad. J. Psycho1., 1966, 20, 343-351.

Ruch, T.C., Patton, H.D., and Brobeck, J.R. Hyperphagia and adiposity in relation to disturbances in taste. Fed. Proc., 1942, 1, 76.

Schmaltz, L.W., and Isaacson, R.L. Effect of bilateral hippocampal destruction on the acquisition and extinction of an operant response. Physiol. Behav., $1967, \underline{2}, 291-298$.

Siega1, A., and Flynn, J.P. Differential effects of hippocampal stimulation upon attack elicited by stimulation of the hypothalamus. Paper read at Eastern Psychological Association Meeting, Boston, 1967.

Singh, D., and Meyer, D.R. Eating and drinking by rats with lesions of the septum and the ventromedial hypothalamus. J. comp. physiol. Psychol., $1968, \underline{65}, 163-166$.

Skultety, F.M., and Gary, T.M. Experimental hyperphagia in cats following destructive mid-brain lesions. Neurology, 1962, 12, 394-401. 
Smith, 0.A. Jr., McFarland, W.L., and Teitelbaum, H. Motivational concomitants of eating elicited by stimulation of the anterior thalamus. J. comp. physio1. Psycho1., 1961, 54, 484-488.

Smith, P.E., The disabilities caused by hypophysectomy and their repair. J. Amer. med. Ass., 1927, 88, 158-161.

Stellar, E. The physiology of motivation. Psychol. Rev., $1954, \underline{61}, 5-22$.

Stevenson, J.A.F. Current reassessment of the relative functions of various hypothalamic mechanisms in the regulation of water intake. In M.J. Wayner (Ed.), Thirst. New York: Pergamon Press, 1964, Pp. 553-567.

Teitelbaum, H., and Milner, P. Activity changes following partial hippocampal lesions in rats. J. comp. physiol. Psychol., 1963, 56, 284-289.

Teitelbaum, P. Sensory control of hypothalamic hyperphagia. J. comp. physiol. Psycho1., 1955, 48, 158-163.

Teitelbaum, P. Random and food-directed activity in hyperphagic and normal rats. J. comp. physiol. Psychol., 1957, 50, 486-491. 
Teitelbaum, P., and Stellar, E. Recovery of the failure to eat produced by hypothalamic lesions. Science, 1954, 120, 894-895.

Thompson, R., Rich, I., and Langer, S.K. Lesion studies on the functional significance of the posterior thalamic mesencepha1ic tract. J. comp. Neurol., $1964,123,29-44$.

Ursin, R., Ursin, $H_{\bullet}$, and Olds, J. Self-stimulation of hippocampus in rats. J. comp. physio1. Psychol., $1966, \underline{61}, 353-359$.

Valenstein, E.S., and Meyers, W.T. Rate-independent tests of reinforcing consequences of brain stimulation. J. comp. physiol. Psychol., 1964, 57, 52-60. White, N.M., and Fisher, A.E. Amygdaloid control of eating behavior. Proceedings of the 73rd Annual Convention of the American Psychological Association, Washington, 1965, 147-148.

Wolf, G., and Sutin, J. Fiber degeneration after lateral hypothalamic lesions in the rat. J. comp. Neurol., $1966,127,135-156$. 
Wyrwicka, W., Dobrzecka, C., and Tarnecki, R. The effect of electrical stimulation of the hypothalamic feeding centre in satiated goats on alimentary conditioned reflexes, type 11. Acta. biol. exper., $1960, \underline{20}, 121-136$.

Wyrwicka, W., and Doty, R.W. Feeding induced in cats by electrical stimulation of the brain stem. Expt. Brain Res., 1966, 1, 152-160. 


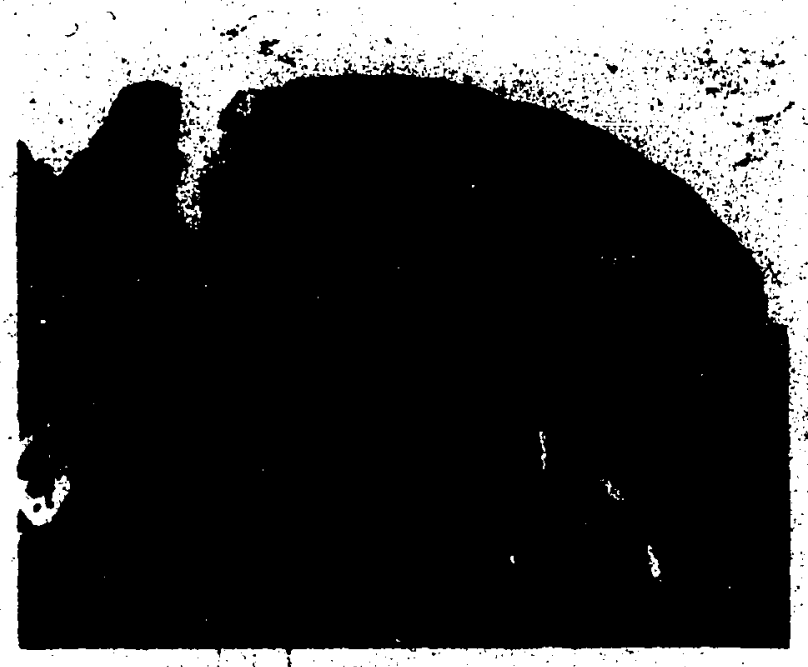

A

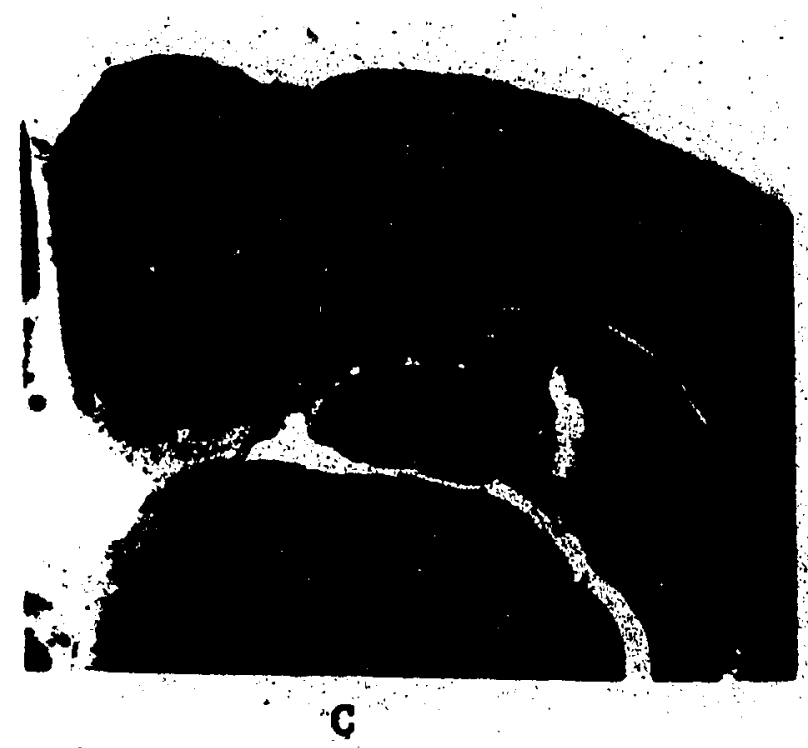

4

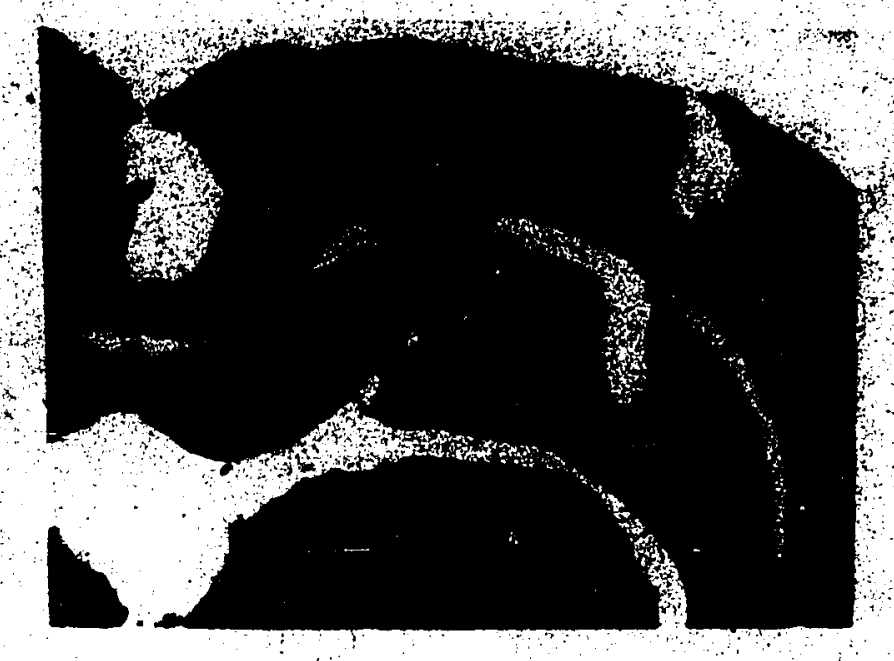

B

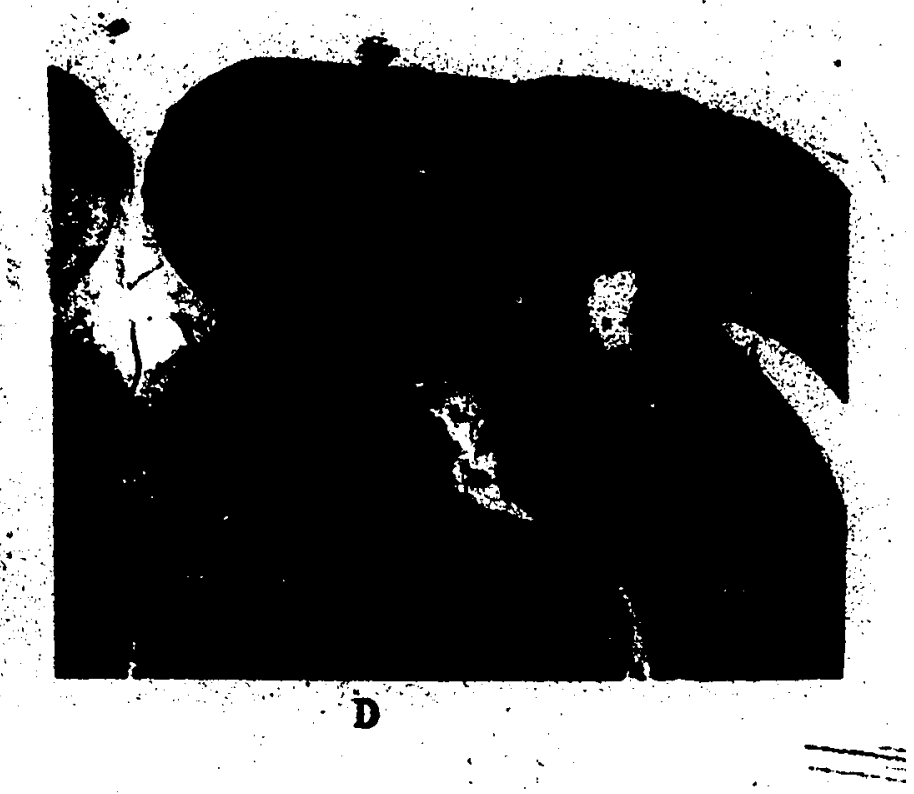

Figure 1. Microphotographs of representative sections. A. Cortical electrode placement.

B. Dentate gyrus electrode placement. C \& D. Hippocampal electrode placements. 


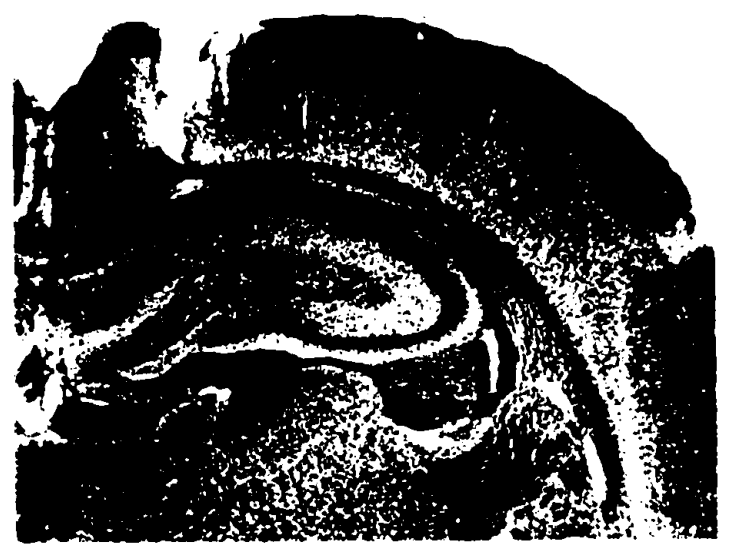

A

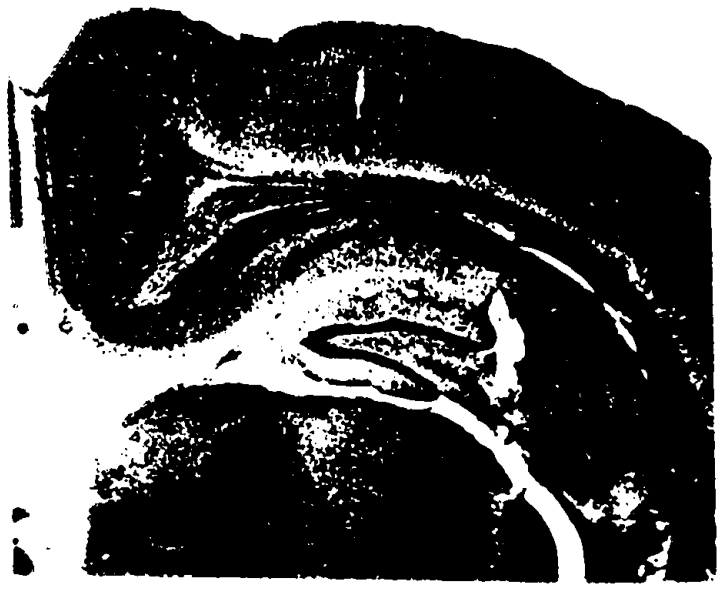

$\mathrm{C}$

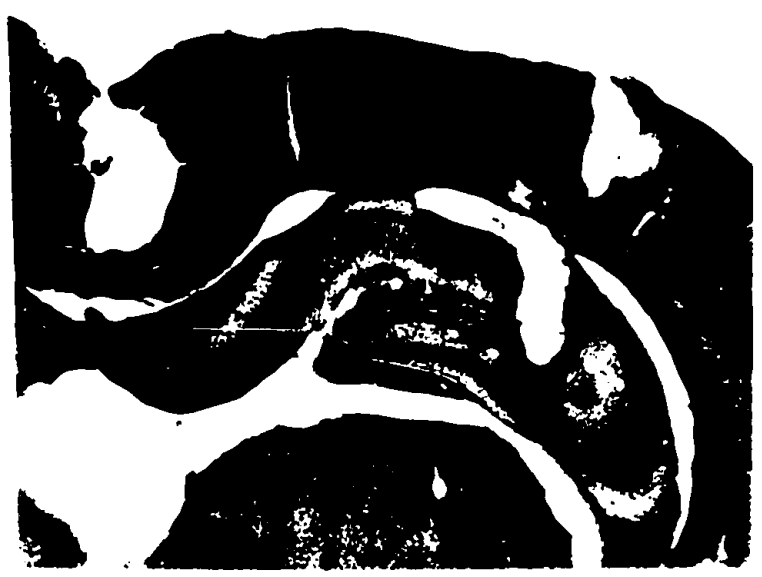

B

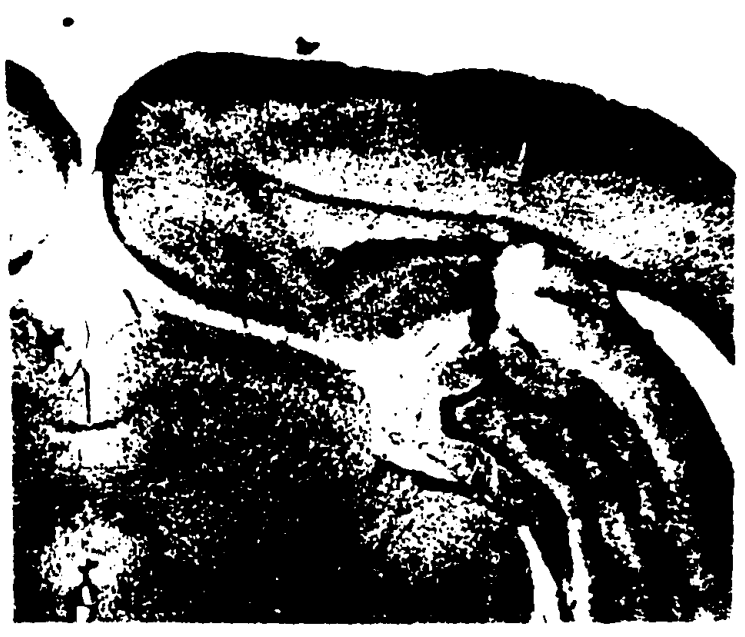

D

Figure 1. Microphotographs of representative sections. A. Cortical electrode placement.

B. Dentate gyrus electrode placement.

C \& D. Hippocampal electrode placements. 
Figure 2. Electrode placements of S's tested for self-stimulation in the Skinner box.

Symbols are: Group 1 - open circle Group 2 - dark triangle Group 3 - dark square Group 4 - dark circle

(See Table 5 for explanation of Group classification) 
- 105 -

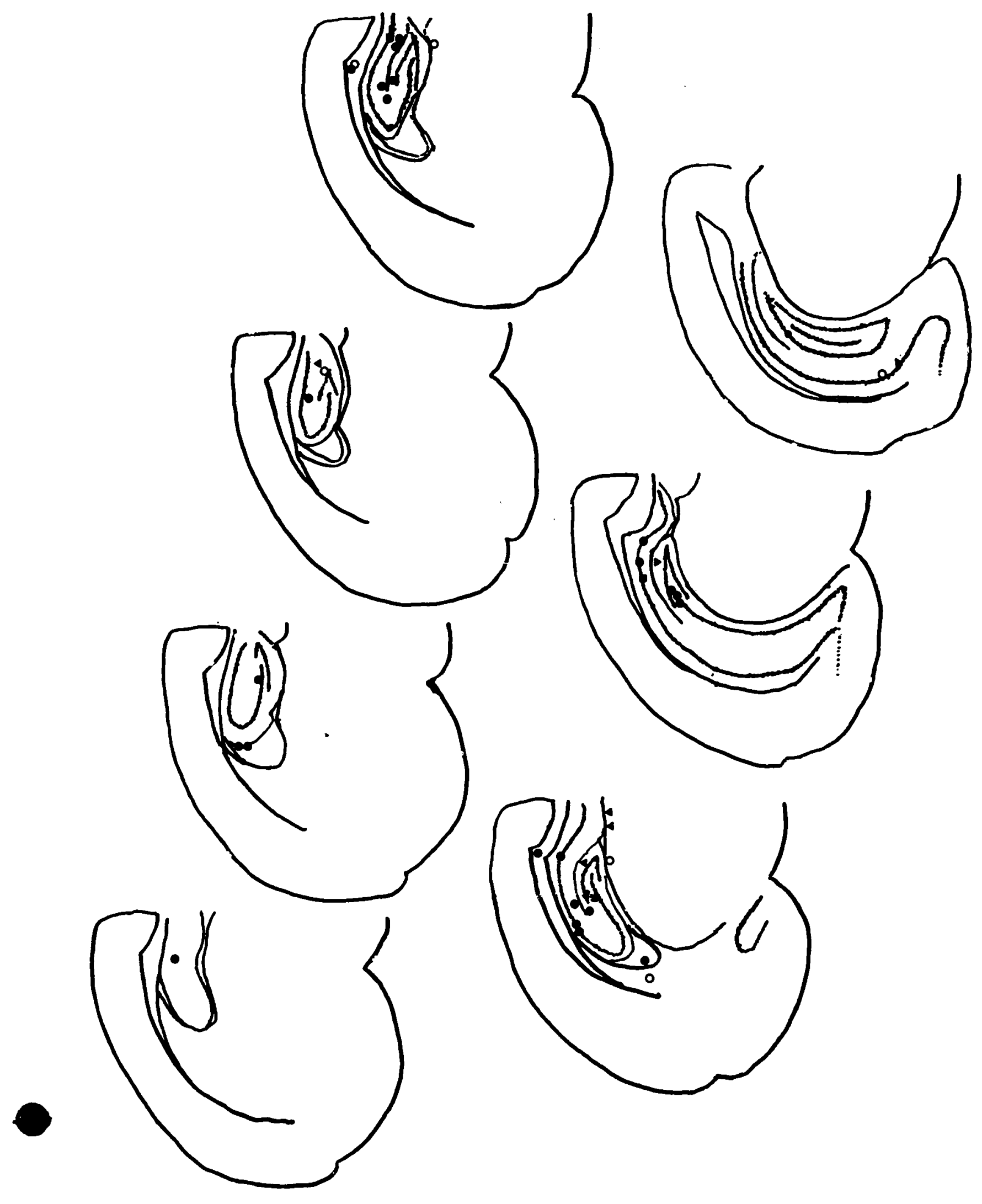




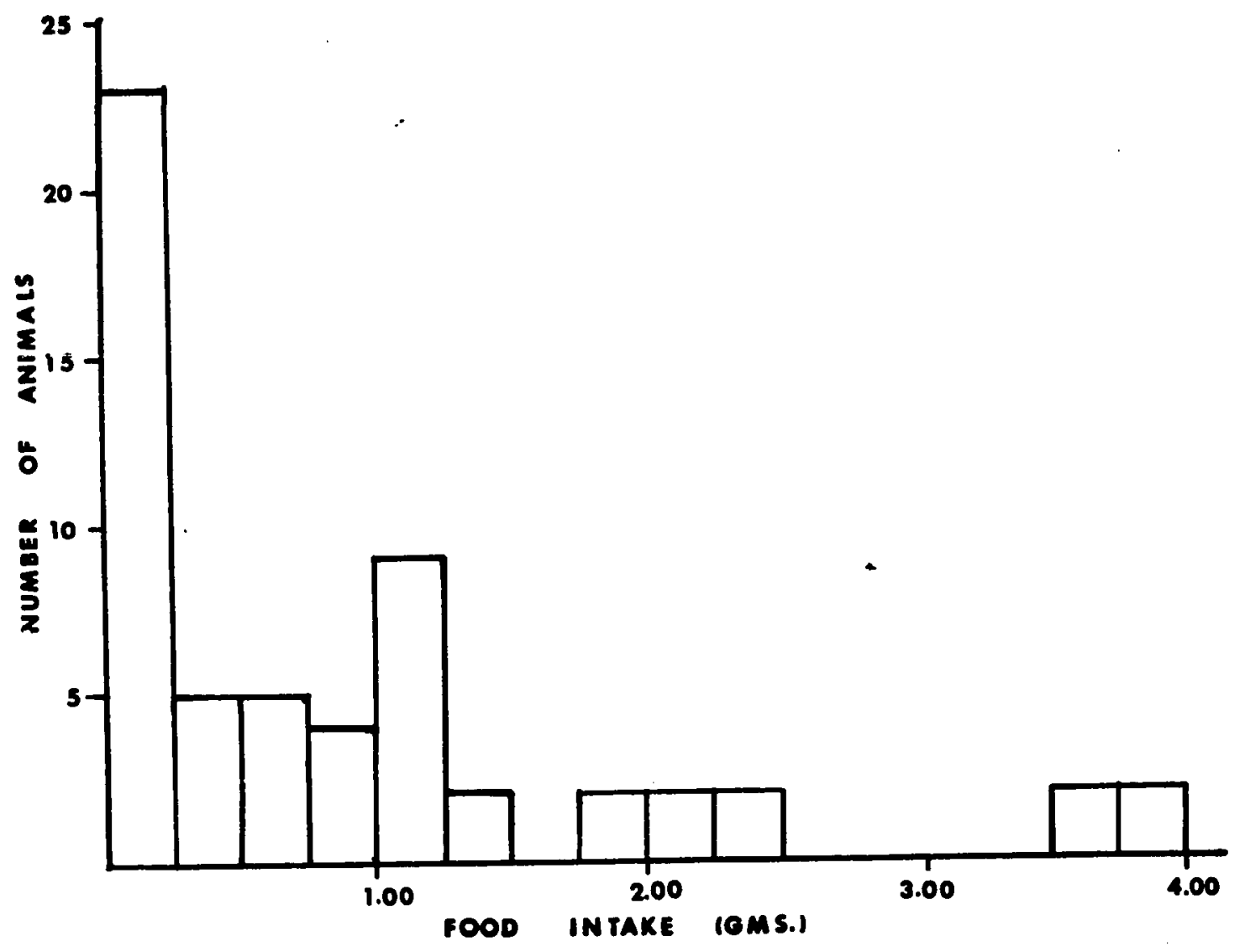

Figure 3. Frequency histogram of food consumption during half-hour no-stimulation condition for 52 S's (see text). 
Figure 4. Electrode placements of S's tested for the effects of stimulation on feeding behavior in the Skinner box. Symbols are: Group 1 - open circle Group 2 - dark triangle Group 3 - dark square Group 4 - dark circle

(See Table 6 for explanation of group classifications.) 


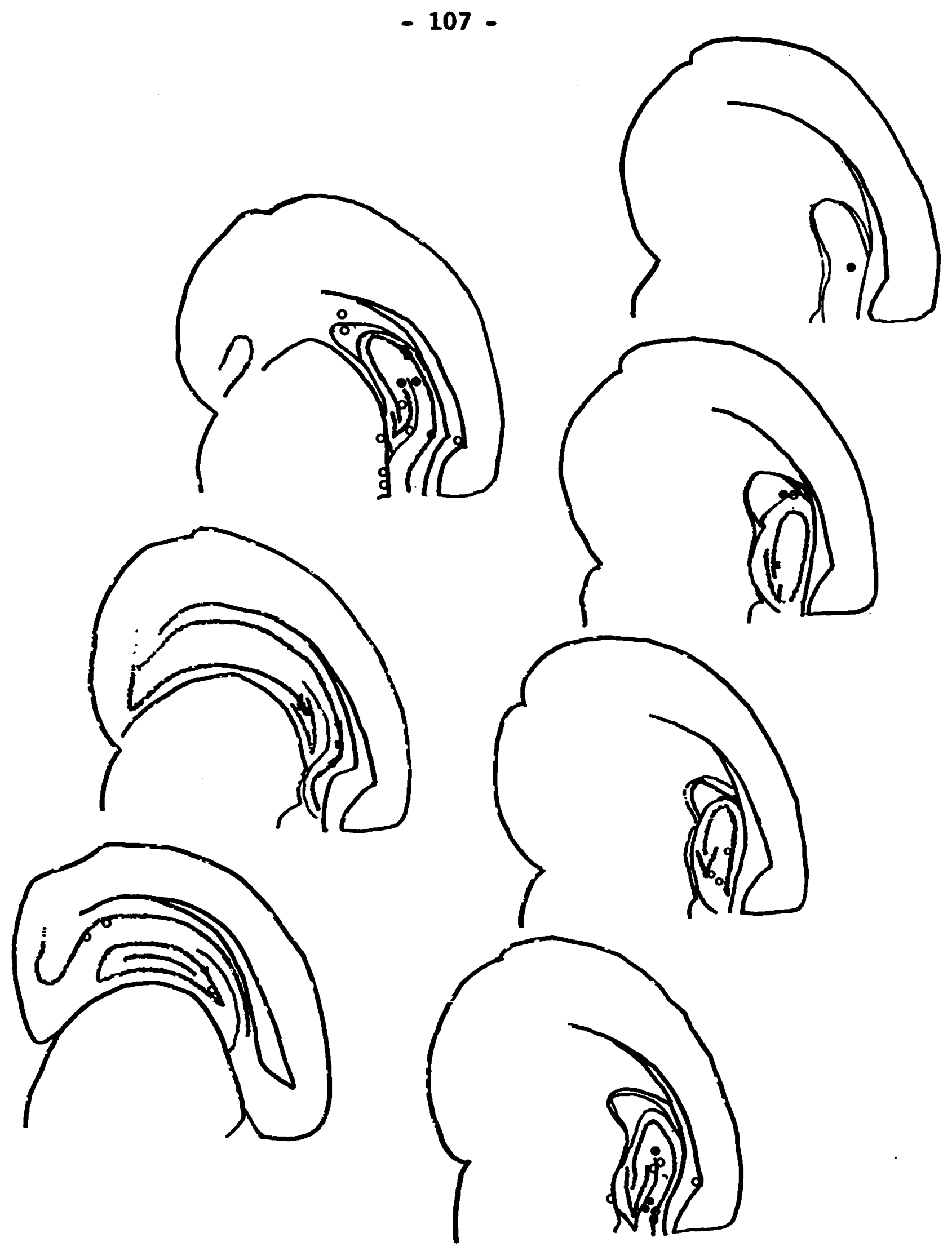




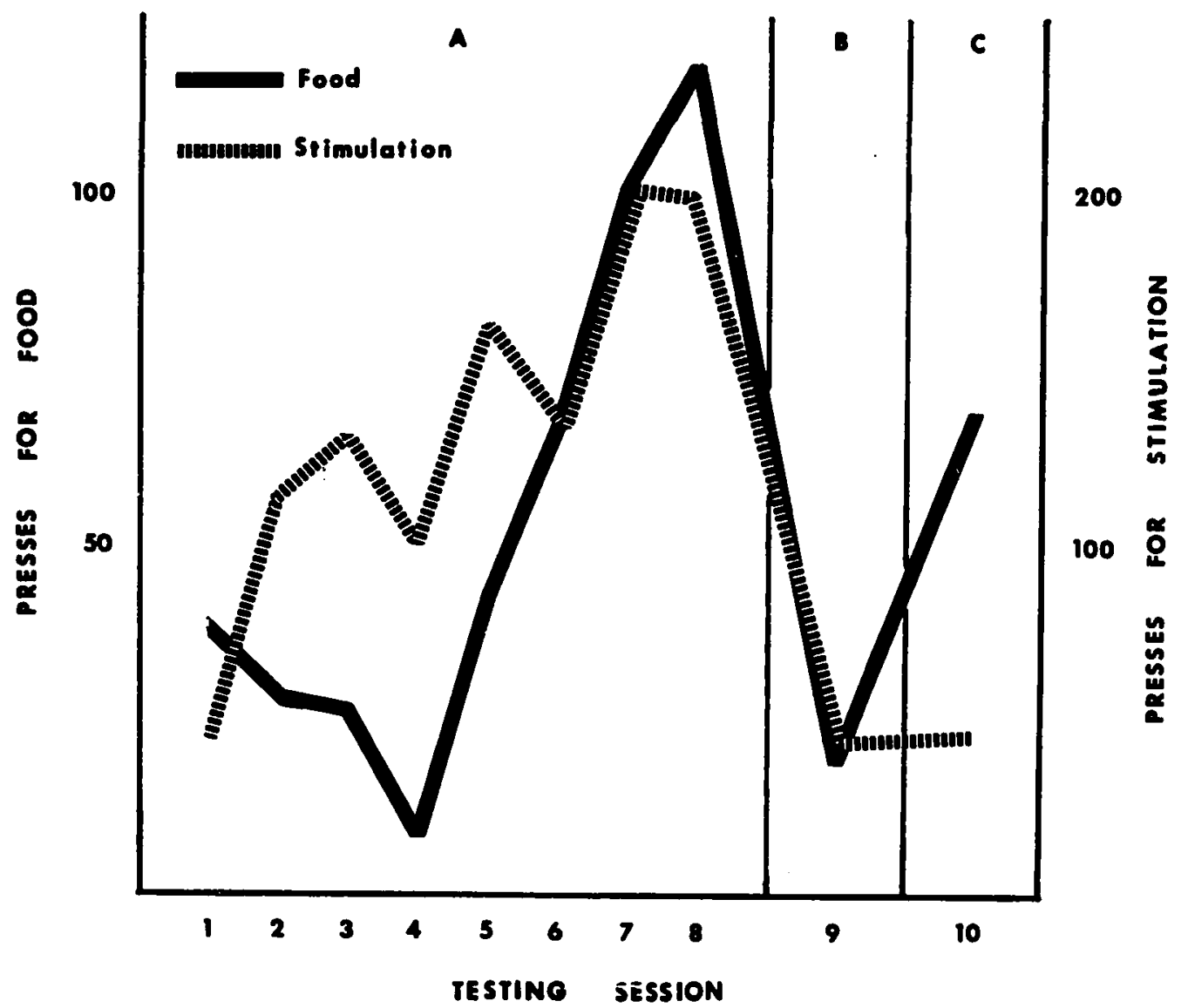

Figure 5. Bar-pressing behavior for one $S$ in the two-bar Skinner box. A. Presses for food and electrical stimulation as a function of experience. B. Presses during no-stimulation conditions. C. Presses during externally delivered hippocampal stimulation. 


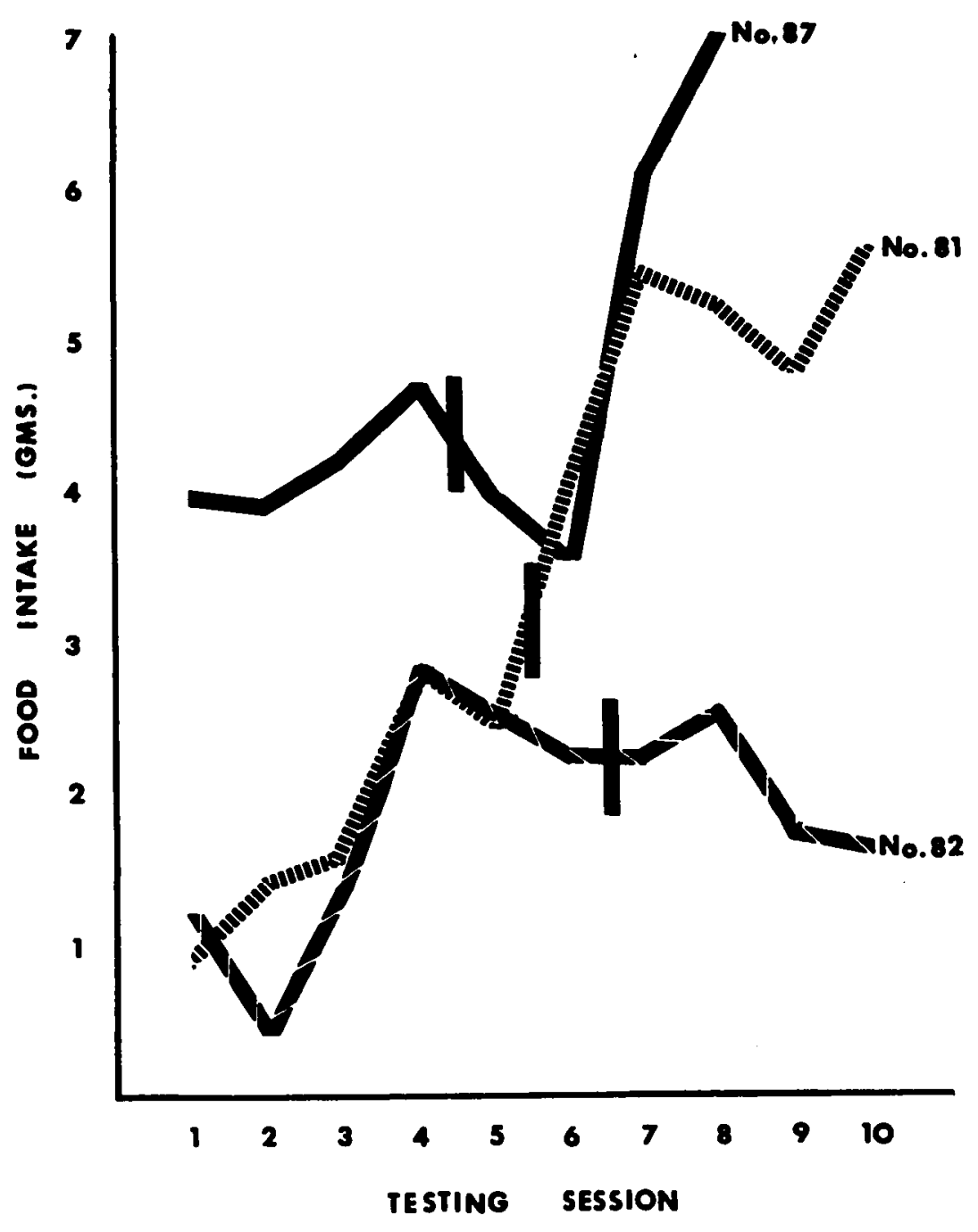

Figure 6. Effects of experience on the feeding elicited by hippocampal self-stimulation for $3 \mathrm{~S}$ 's. Day 1 is the day after the animals learned to self-stimulate. Vertical lines represent time of second operation (e.g., rat number 82 was operated upon between days 6 and 7). 


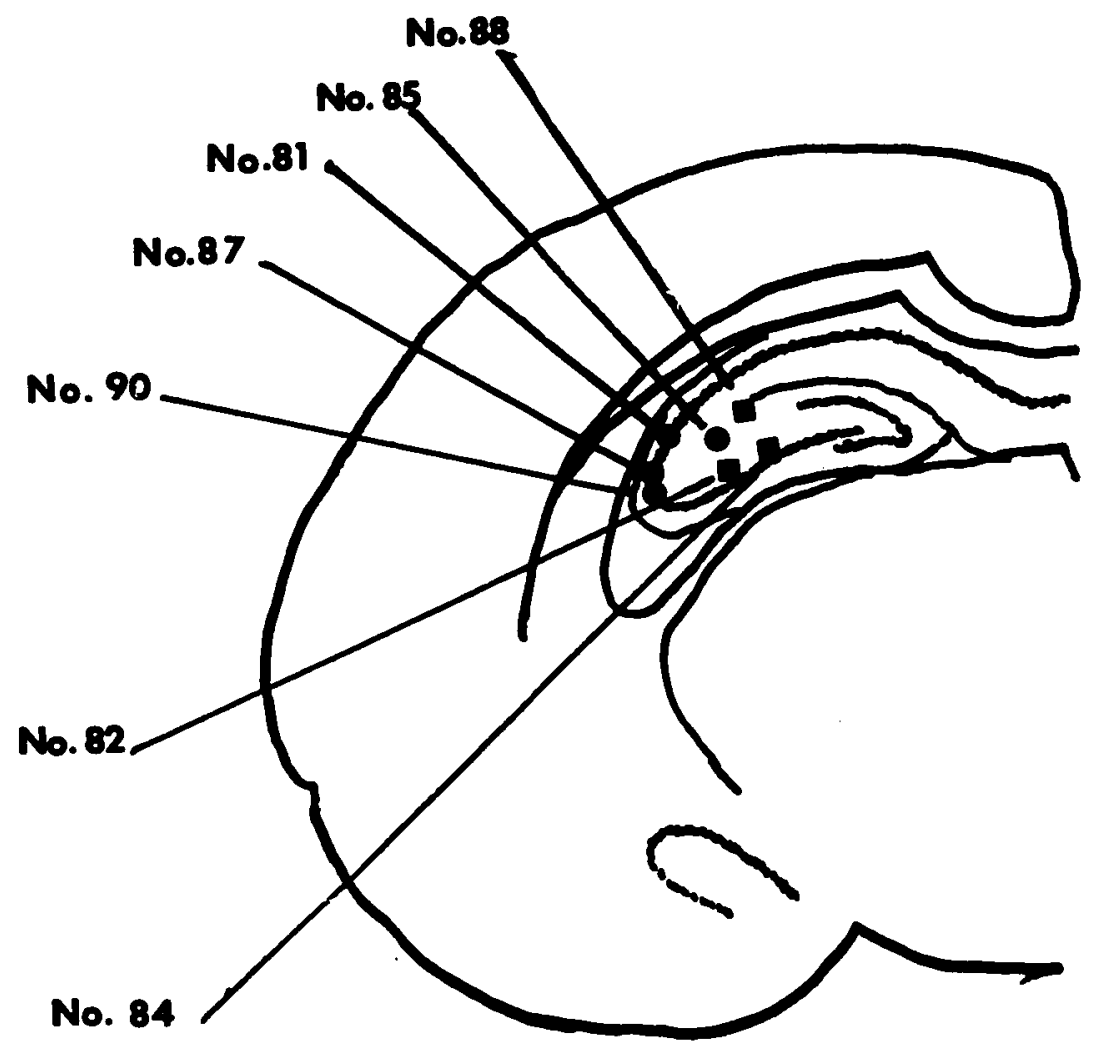

Figure 7. Location of electrode tips for S's in experiment three. 
Figure 8. Representative drawings of damage caused by fimbria cuts.

A. Smallest lesion (rat 87).

B. Representative of cuts completely destroying dorsal fornix (rat 85).

C. Largest lesion (rat 85). Note that lateral fimbria is still intact. 

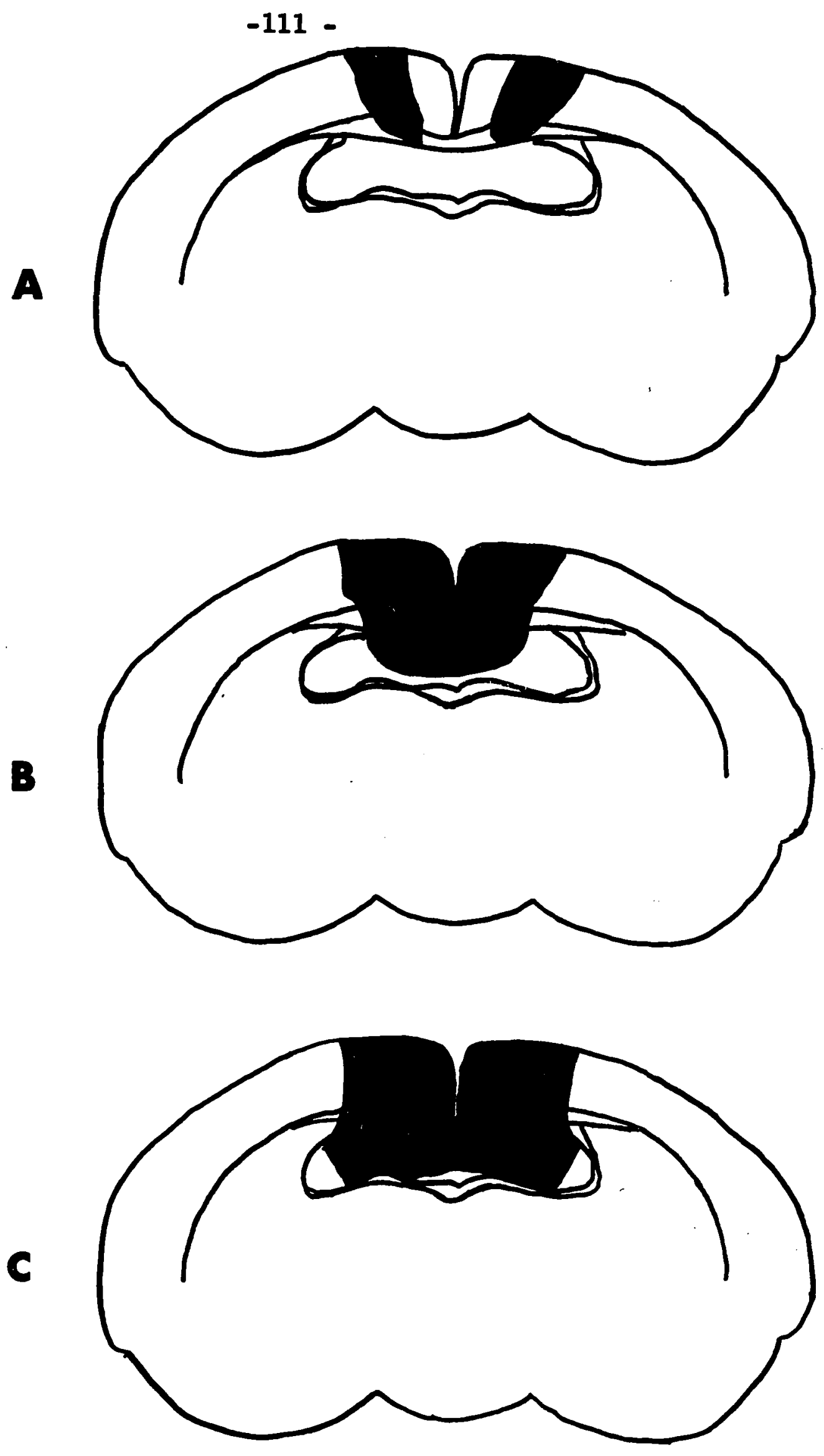